\title{
EL VOLCÁN CHILIQUES Y EL "MORAR-EN-EL- MUNDO" DE UNA COMUNIDAD ATACAMEÑA DEL NORTE DE CHILE
}

\author{
Ricardo Moyano y Carlos Uribe ${ }^{2}$
}

\section{* Introducción}

Resumen

En este trabajo se muestran los resultados preliminares del reconocimiento arqueológico del volcán Chiliques $\left(23^{\circ} 34^{\prime} \mathrm{S} / 67^{\circ} 42^{\prime} \mathrm{W}\right.$ / 5778 m.s.n.m.), desierto de Atacama, norte de Chile. El objetivo fue confirmar la existencia de sitios arqueológicos en la zona, así como una posible línea ceque proyectada desde el centro ceremonial de Socaire. Los resultados confirman la importancia del volcán Chiliques como propiciador de fenómenos meteorológicos dentro del sistema de montañas sagradas invocadas para la ceremonia de limpia de canales del mes de octubre en Socaire. Chiliques habría constituido un "axis mundi" por las siguientes razones: su forma cónica y visibilidad permanente desde otros adoratorios prehispánicos, la existencia de dos lagunas en su cumbre (elemento ctónico), su localización geográfica en el horizonte este y las características naturales del terreno que dan origen a la quebrada de Nacimiento.

Palabras claves: Chiliques - Socaire - calendario agrícola.

This article presents the preliminary results from the archaeological

Abstract survey of the Chiliques Volcano ( $23^{\circ} 34^{\prime} \mathrm{S} / 67^{\circ} 42^{\prime} \mathrm{W} / 5778$ masl) situated in the Atacama desert, northern Chile. The main goal was to verify the existence of archaeological sites in the area, as well as a possible ceque line projected from the ceremonial center of Socaire. The results suggest the importance of Chiliques Volcano as a facilitator of methereological phenomena within the system of sacred mountains which are invoked during the ceremony for cleaning the canal held in October in Socaire. Chiliques might have constituted an "axis mundi"

for the following reasons: its conical shape and permanent visibility from other prehispanic shrines, the existence of two lakes in its summits (ctonic element), its geographical location at the eastern horizon and the natural characteristics of the soil at the origin of the Nacimiento Ravine.

Key words: Chiliques - Socaire - Agricultural Calendar.
El volcán Chiliques corresponde a un estrato volcán de 5778 m.s.n.m., ubicado en la Región de Antofagasta, norte de Chile ( $23^{\circ} 34^{\prime} \mathrm{S}, 67^{\circ} 42^{\prime} \mathrm{W}$ ) (Figura 1). Esta montaña no habría registrado actividad volcánica durante los últimos 10.000 años, sin embargo, en enero de 2002 una imagen infrarroja obtenida por ASTER (Advanced Spaceborne Thermal Emission and Reflection Radiometer) de la NASA, reveló ciertos hot spots en una zona cercana al cráter y edificio volcánico. ${ }^{3}$

En las inmediaciones de la cumbre principal a 5727 m.s.n.m., los antecedentes arqueológicos dan cuenta de una estructura elíptica con roca central de diámetro mayor (N-S) de $8 \mathrm{~m}$ con abertura al este, una pequeña habitación de 2 × 2,4 m con tierra roja en su interior adosada a la elipse, cerámica negro sobre rojo, y dos emplazos rectangulares yuxtapuestos con ejes mayores E-W (6 x 5 $\mathrm{m})$. Además, se encontraron nueve habitaciones a 5680 m.s.n.m., un complejo de pircas a 5315 m.s.n.m., un tambo de 53 estructuras a 4500 m.s.n.m., cerámica incaica y un tramo del Qhapaq Nan por la ladera norte hasta la cumbre (Beorchia 2001: 288; Reinhard 1983, 1993 Ms).

Agüero y Ayala (2007) señalan la existencia de cerámica local e inka-local en la cumbre y en el campamento base (tambo Chiliques), representado por cántaros y aríbalos rojo revestidos. Dan cuenta además de cántaros, ollas y

Recibido: enero 2010. Aceptado: diciembre 2011.

\footnotetext{
${ }^{1}$ Arqueólogo. Estudiante de Posgrado, Escuela Nacional de Antropología e Historia. Periférico Sur y Zapote s/n, Col. Isidro Fabela, México D.F. C. P. 14030. MÉXICO. Email: mundosubterraneo2@yahoo.es

2 Licenciado en Arqueología, Universidad de Chile. San Esteban 1671-H, depto. 23, Villa Alonso de Ercilla, La Florida, Santiago, CHILE. Email: hombresinrostro@hotmail.com

3 http://visibleearth.nasa.gov/view__rec.php?id=2632
} 
aríbalos de los tipos Yavi, inka-local, Turi Rojo Alisado, rojos revestidos, Ayquina y Hedionda.

La evidencia etnográfica (Barthel 1986; Reinhard 1983) confirma la importancia de esta montaña como propiciadora de los fenómenos metereológicos, al ser la invocada durante la ceremonia de limpia de canales del mes de octubre en Socaire. Para esta fecha, los cantales (especialistas rituales) invitan a las montañas a comer y a beber (pago ritual), para que concentren sus aguas en Chiliques. De allí que se le considere como un "habilitador" en el contexto de una politización del espacio ritual, es decir, una huaca a través de su representación a escala, por medio de una gran roca en el mero centro ceremonial de Socaire (Barthel 1986).

Astronómicamente, desde las cercanías del centro ceremonial de Socaire, se ha constatado la existencia de un marcador solar de horizonte en la cumbre norte de volcán Chiliques para el día 24 de agosto (fiesta de San Bartolomé). Para esta fecha, el Sol inicia su recorrido diario con un acimut de $74^{\circ} 13^{\prime}$, relacionando visualmente la fiesta del santo, la montaña y la observación solar (Moyano 2011: 101).

La etnografía reciente (Moyano 2010, 2011) sugiere al Chiliques también como parte de la proyección de una mano izquierda en el horizonte, compuesta por los volcanes Tumisa, Lausa (Lejía), Chiliques, Ipira (Miscanti) y Miñiques. Esta etno-representación de la figura humana en el paisaje, desde nuestro punto de vista simbolizaría la medida social del tiempo y la diferenciación entre los días cortos, cercanos al solsticio de junio y el horizonte del volcán Lausa, en oposición con los días largos cercanos al solsticio de diciembre y el volcán Ipira (Figura 2).

Chiliques o Chiuliques como montaña principal del grupo de cerros sagrados de Socaire se le conoce como "cerro mocho", vinculándose directamente con San Bartolomé y la fiesta del 24 de agosto pues "...ambos carecen de cabeza y son mochos". Según los socaireños, aquí nace el agua, el canal y el sustento de la comunidad. De allí, que muchos crean que el mismo Inka anduvo por estas tierras e incluso que habría amarrado un toro a un tronco en la misma cumbre del volcán. Hace algunas décadas, incluso era común que los habitantes del poblado fueran caminando a las faldas del volcán, ya sea buscando mejores pastos para sus animales o animados por las historias con respecto al tesoro de los inkas. La tradición comenta que Don Raymundo Consue conoció de primera vista la "casa del Inka" (tambo Chiliques) y encontró madera en el camino, que según él constituía "señal de riqueza". Que Don Nemesio Varas encontró madera y un cacho de toro, suponemos en las cercanías de la cumbre. Y que tanto los cerros Chiliques y Salín "se unen visualmente por una línea" (Moyano 2010: 193).

Sugerimos la naturaleza de esta montaña como una huaca por las siguientes razones: 1) forma cónica y visibilidad permanente desde otros adoratorios prehispánicos; 2) existencia de dos lagunas en su cumbre (elemento ctónico); 3) localización geográfica en el horizonte este -cercana a la posición del Sol para el 24 de agosto- día del San Bartolomé (Santo Patrón de Socaire); y 4) lugar de origen de las aguas de la quebrada de Nacimiento y el sistema hídrico de Socaire.

Exponemos los resultados preliminares del estudio de la huaca volcán Chiliques, en el contexto de recientes trabajos etno-astronómicos y calendáricos en Atacama (Moyano 2010, 2011), entendiendo a éstos como ejes estructurales de un desarrollo teórico y metodológico que intenta integrar la arqueología de alta montaña, los estudios del paisaje, la astronomía cultural y la fenomenología en la comprensión de los distintos procesos culturales en el área del salar de Atacama.

\section{* Consideraciones metodológicas}

La arqueología de alta montaña implica no solo una preparación intelectual y física, sino también logística para el logro de los objetivos propuestos. La ascensión y reconocimiento arqueológico del volcán Chiliques se realizó entre los días 22 y 26 de diciembre de 2008 . El itinerario partió desde el poblado de Socaire por la ruta que une este lugar con la laguna Lejía, ubicada a 4300 m.s.n.m., y el salar de Aguas Calientes. Por las condiciones de desnivel y altitud (cota máxima 5778 m.s.n.m.), fue necesario portear agua y peso desde la cota 4400 m.s.n.m., Meseta del Inka (donde nos dejó la camioneta 4 × 4), hasta el campamento base en las cercanías del tambo Chiliques (4569 m.s.n.m.), en tres oportunidades. Una vez en el tambo Chiliques (UTM $19 \mathrm{~K}$ $0632407 \mathrm{E}, 7394612 \mathrm{~N}$ ), nos dedicamos las dos primeras 


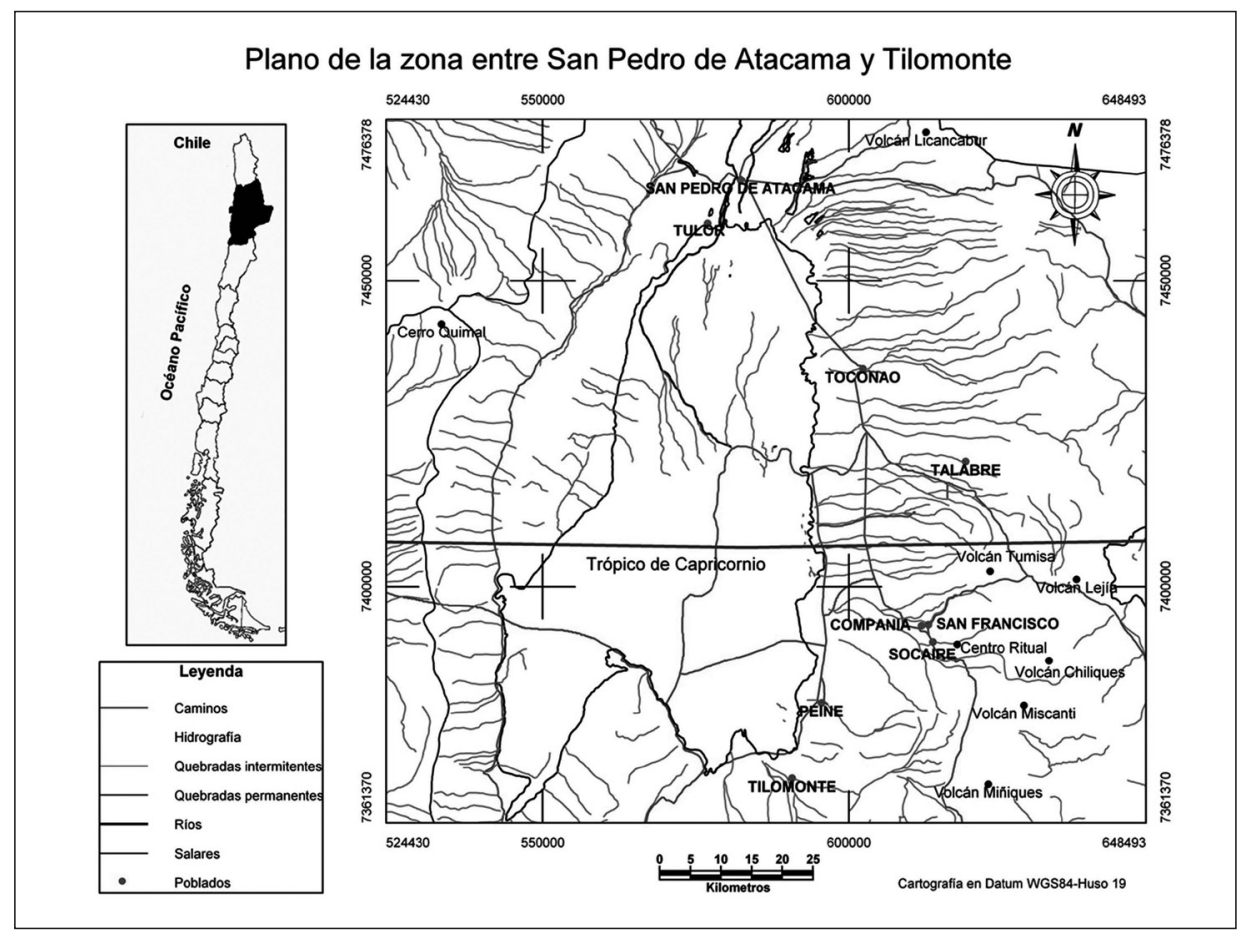

Figura 1. Mapa geográfico de la ubicación de Socaire y sus entornos.

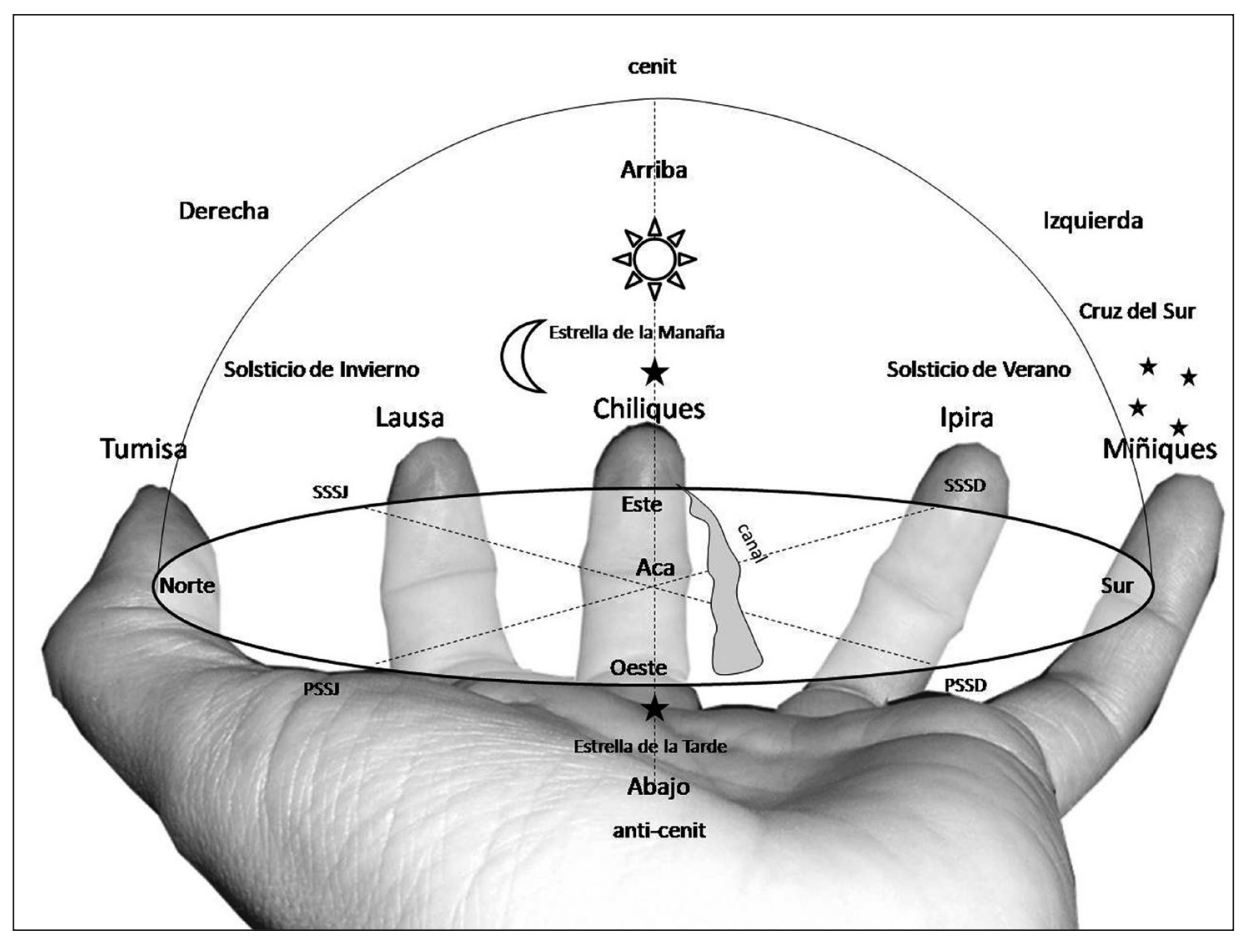

Figura 2. Esquema de la cosmovisión de Socaire (Moyano 2010). 
jornadas a realizar una adecuada aclimatación y luego subir al campamento alto (UTM $19 \mathrm{~K} 0633230 \mathrm{E}, 7393800$ N, 4840 m.s.n.m.), desde donde se atacó la cumbre principal el día de navidad a las 06: 15 horas (Figura 3).

Debido a las condiciones del terreno (altitud, falta de oxigeno relativa, fuertes vientos y bajas temperaturas), fue necesario el uso de ropa y equipo de alta montaña, que incluyó la preparación física, el adiestramiento en el uso del piolet de marcha y la caminata en zigzag para enfrentar la pronunciada pendiente, principalmente en la última parte del ascenso. El objetivo en campo fue georeferenciar, fotografiar y describir los recursos patrimoniales de tipo arqueológico en la zona tambo-RPC, camino, estructuras y material arqueológico en superficie), rasgos distintivos del paisaje como cerros, quebradas, lagunas y mesetas en relación a factores de orientación, visibilidad e intervisibilidad, así como la constatación de la orientación norte-sur del eje mayor del tambo Chiliques (Beorchia 1985: 71-72) y la de sus vanos en dirección este. Se opto por seguir la numeración y nomenclatura realizada por Reinhard, Barón y Serracino, resultado de dos expediciones en octubre de 1980 (Beorchia 1985; Reinhard 1993 Ms), así como los croquis y material no publicado proporcionado por Agüero y Pimentel, resultado de un reconocimiento del tambo y camino incaico realizado en 2003.

Para el registro, se utilizó un cuaderno de notas, una cámara digital (Nikon 4100), una brújula magnética (precisión $1^{\circ}$ ), un GPS Garmin Legend (Datum WGS 84), un teodolito/tránsito Berger, Modelo ST-1 (precisión 1'), además de la utilización de fotografías aéreas, la carta topográfica del Instituto Geográfico Militar (Toconao 1: 125.000) e imágenes satelitales del programa Google Earth. El cálculo para la declinación del Sol con respecto a marcadores del paisaje se realizó gracias a un sistema de referencia de horizonte. El análisis astronómico de fechas y declinaciones se llevó a cabo con los simuladores StarCalc 5.72 y Moshier's Ephemeris Program 5.1, junto con los datos entregados por Astronomical Almanac (EE. UU.), IGIK (Polonia) y el Anuario del Observatorio Nacional de México, UNAM.

Los resultados del reconocimiento arqueológico se encuentran supeditados a las condiciones del terreno (visibilidad, acceso y distancia), al factor tiempo y a la dinámica de los agentes naturales del sector (rodados y

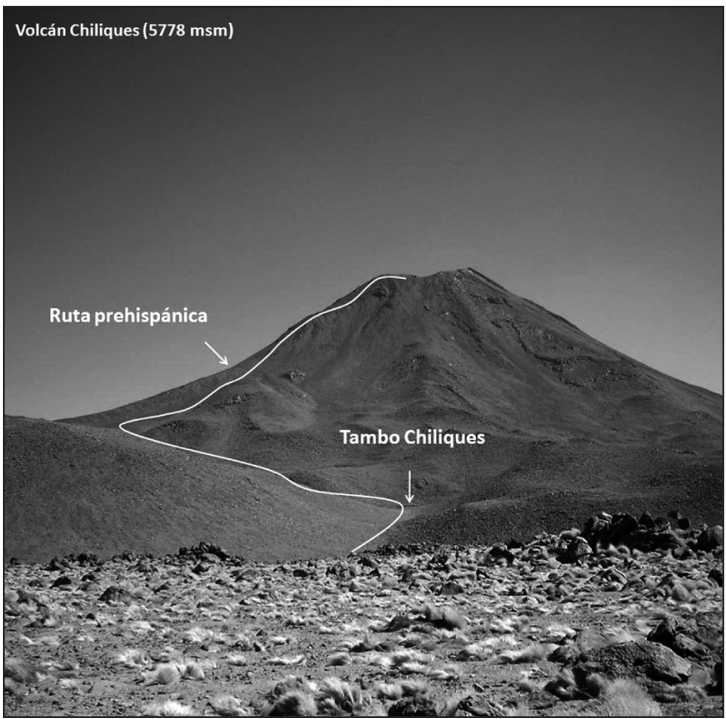

Figura 3. Vista general del volcán Chiliques, cara norte.

deslizamientos de terreno). El trabajo de registro en la cumbre misma del Chiliques se redujo a una hora y media. Para bajar se optó por la ruta del acarreo norte, más rápida, pero también peligrosa, por la fuerte pendiente y la caída de material. Por desgracia, no se dio con el conjunto de estructuras a los 5300 m.s.n.m. La sistematización de los datos se complementó con información etnográfica de primera mano (observación participante) obtenida entre los meses de diciembre de 2008 (solsticio de verano) y octubre de 2009 (limpia de canales), así como del uso de distintas fuentes escritas y documentales publicadas desde la década de 1950 a la fecha.

\section{* El calendario agrícola en Socaire}

"Santiago de Socaire" 4 es una comunidad Atacameña o Likan Antai ubicada al sureste del salar de Atacama (3274 m.s.n.m., $\left.23^{\circ} 35^{\prime} \mathrm{S}, 67^{\circ} 52^{\prime} \mathrm{W}\right) .^{5}$ Aparentemente tendría un origen prehispánico y un sistema radial de organización

\footnotetext{
4 Mostny (1954: 22-23) da cuenta del nombre original del poblado, de donde se asume un posible vínculo con Santiago apóstol y la fiesta del 25 de julio, anterior al siglo XVIII como atestiguan las fuentes parroquiales (Pino Manrique 1787).

5 Socaire: situación protegida del viento por cualquier accidente que se anteponga a él, en castellano. http: //www.wordreference. $\mathrm{com} /$ definicion/socaire (accesado el 11 de julio de 2010).
} 


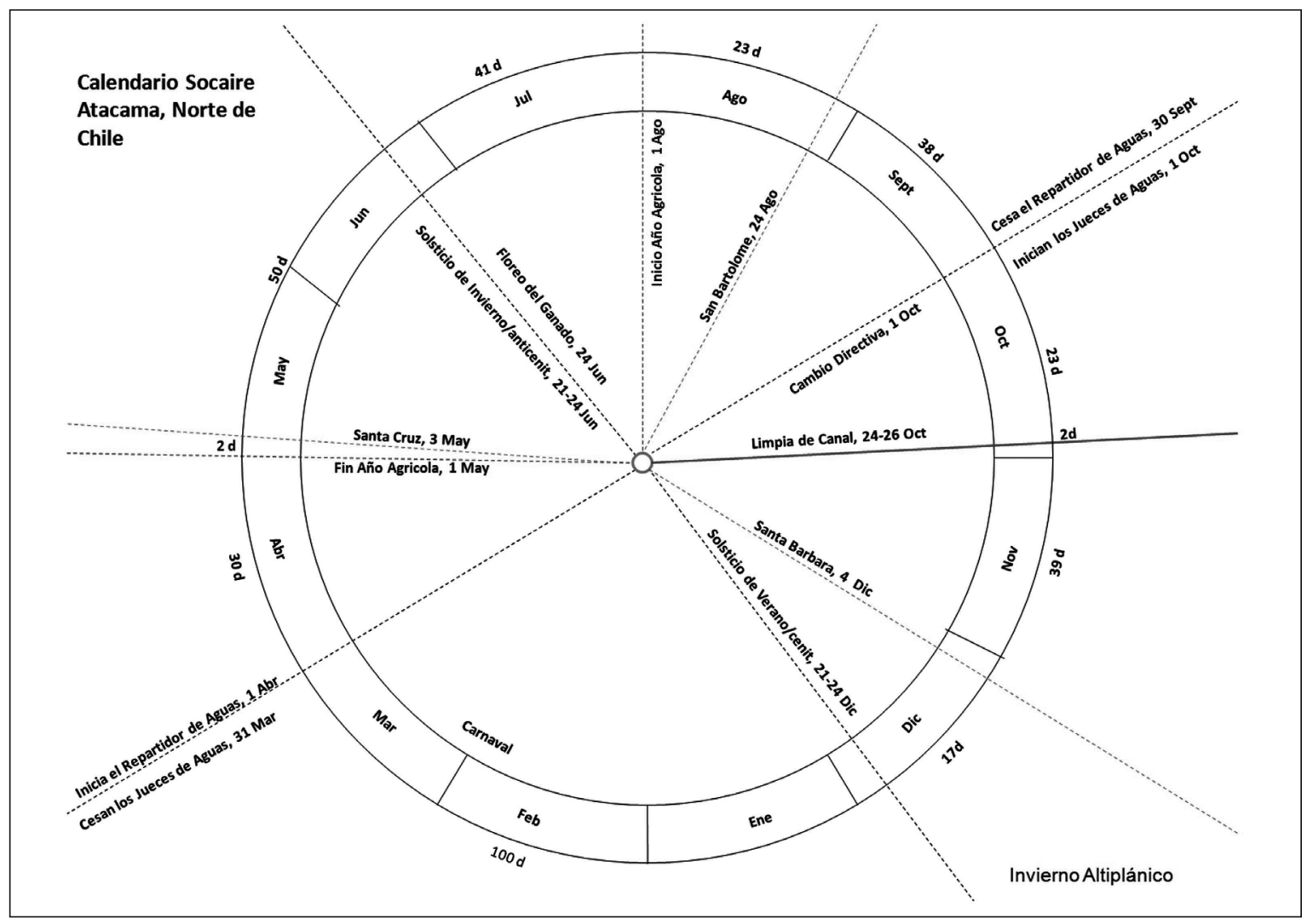

Figura 4. Calendario de Socaire.

con seis barrios: tres arriba, tres abajo, más uno central (Hidalgo 1992). Su posición geográfica, $16 \mathrm{~km}$ al sur del trópico de Capricornio, genera un evento astronómico de singulares características, que es la coincidencia del paso cenital del Sol, es decir, en un ángulo de 90 grados con respecto al observador, para fechas cercanas al solsticio de diciembre, inicio del verano calendárico en el hemisferio sur (Moyano 2011). ${ }^{6}$

El calendario anual en Socaire, hasta mediados de la década de 1980, incluía fechas prehispánicas y cristianas, organizadas de la siguiente manera: 1 de agosto (inicio del año agrícola), 24 de agosto (fiesta de San Bartolomé),

6 Con respecto al cenit, la palabra quechua sayhua "mojón" o "lindero" hace referencia también a ticnu "el zenit o punto de la mitad del cielo" o momento del día cuando el Sol está por sobre las cabezas (mediodía) (González Holguín 1952; Sanhueza 2005: 61; Santo Tomás 1951 [1560]).

7 Agosto se reconoce como un período importante del año. Este
30 septiembre - 1 octubre (cambio de directiva: deja el repartidor $\mathrm{y}$ asumen los jueces de aguas), 24-26 de octubre (limpia de canales), 4 de diciembre (fiesta de Santa Bárbara), fines de febrero-inicios de marzo (carnaval), 31 de marzo-1 de abril (dejan los jueces y asume el repartidor de aguas), 1 de mayo (fin del año agrícola), 3 de mayo (fiesta de la Santa Cruz) y 24 de junio (fiesta de San Juan y floreo de los animales) (Barthel 1986; Hidalgo 1992) (Figura 4).

mes se dedica a la fiesta del santo patrón, al cual se vincula con la fertilidad, el agua y el ganado de cabras. De allí que el 24 de agosto "...se le pide por el agua" (Jeannette Cruz, com. pers. octubre 2009). De acuerdo con Josefa Cruz, se le asocia también con el color rojo, "un color fuerte", con la piel descarnada y los decapitados. Su culto fue introducido en el año de 1955, con la primera misa oficiada por el religioso y arqueólogo belga Gustavo Le Paige, venido desde San Pedro de Atacama. En su honor, además de la imagen que se tiene en la iglesia nueva, existen dos cruces en lo alto del poblado, una orientada al Miscanti (Ipira) y la otra al Lejía (Lausa) (Moyano 2010: 175). 
Estas fechas generan una división del año en dos mitades, de seis meses cada una, para los cargos de los jueces y el repartidor de aguas. Así como otra subdivisión en 23 , $38,23(+2), 39,17,100,30(+2), 50$ y 41 días, si incluimos el paso cenital del Sol, que para esta latitud coincide con el solsticio de diciembre (Moyano 2010, 2011).

Esta división del año denota cierta regularidad, al menos dentro de la primera parte del año entre el inicio del año agrícola y la fiesta de Santa Bárbara, igual a $23+38+$ $23(+2)+39$ días. De la misma manera, el recambio de los cargos de jueces y repartidor de aguas genera la división del año en dos: entre el 1 de octubre y el 31 de marzo; y entre el 1 de abril y el 30 de septiembre. Quedando implícitas las categorías de tiempo de trabajo y descanso de la tierra. El primero, entre el 1 de agosto y el i de mayo, es conocido etnográficamente como "año de riego". El segundo, conocido como el "período de descanso", es cuando se aprovecha además para marcar los animales.

La ceremonia de limpia de canales se realiza regularmente entre el 24 y el 26 de octubre, o en el fin de semana más cercano a estas fechas.8 En ella se realiza la petición de lluvias, invocando a los cerros de la región desde el centro ceremonial de Socaire, ubicado a $6 \mathrm{~km}$ del poblado, cerca de la bocatoma de agua en la quebrada de Nacimiento.

El centro ceremonial se compone de: 1) un círculo de piedras planas con dimensiones de 4 × $5 \mathrm{~m}$, llamado "merendadero" (Barthel 1986: 154); 2) dos piedras perpendiculares ubicadas al este del merendadero, la mayor

\footnotetext{
8 Omac Raymi, Homa Raymi - Octubre: Se llevaba a cabo en el pueblo de Uma (San Jerónimo), donde se armaban los caballeros inka, es decir, los inkas de privilegio. Las festividades tenías dos aspectos principales: 1) En Uma: "que es legua y media de la ciudad; a los cuales hizo merced y a los Ayarmacas, y a los Quivios, y a los Tambos que se pudiesen horadar la orejas, con tal que no se cortasen los cabellos orque se conociesen que eran súbditos del Cuzco porque los orejones dél (que) eran los señores y los que lo habían de ser en toda la tierra, tenían tusado el cabello y aguzadas las cabezas para arriba, por la cual señal habian de ser conocidos portoda la tierra" (Betanzos 1968, cap. XVIII: 56); y 2) En Cusco se llevaba a cabo una ofrenda de cien carneros (iblancos?) para la petición de lluvias. “...si faltaba agua en este mes, ponían atado a un llamo un carnero escogido de los del sol que fuese todo negro, y derramaban alrededor dél cantidad de chicha con ciertas ceremonias. No le daban de comer cosa alguna hasta que lloviese..." (Cobo, loc. cit. Cap. XXIX: 219). Por desgracia no se tiene una fecha fija para esta ceremonia, solo se puede recalcar la importancia del pase del Sol por el cenit en la latitud del Cusco (entre el 29 y 30 de octubre) (Ziólkowski 1987: 205-206).
}

representaría la piedra "macho" y al volcán Chiliques, y la menor a la "hembra" (Hidalgo 1992: 376-377); 3) otra piedra conocida como "cerro grande" al suroeste de merendadero (Hidalgo 1992: 376-377); 4) el "covero" o sector plano junto a cerro grande donde se queman distintos tipos de ofrendas (Barthel 1986: 154-155); y 5) un sistema de gradas al norte donde toman lugar los asistentes a la ceremonia.

La petición de lluvias es realizada por dos cantales (especialistas rituales), quienes invocan a los cerros del grupo sur y del grupo norte para que concentren sus aguas en el volcán Chiliques. ${ }^{9}$ La rogativa parte por los cerros del sur, siguiendo el sentido de las manecillas del reloj, partiendo por Litinque (o Liquintique) (4760 m.s.n.m.) sobre la línea equinoccial. Para los cerros del grupo norte, se sigue la orden inversa y partiendo desde Lausa o Lejía (5793 m.s.n.m.). Cada cerro será invocado a través de botellas de aloja (chicha de algarrobo), plumas de flamenco, manteca y comida, acompañado de un canto y baile ritual conocido como Talatur (saltar o dar brincos en Kunza) (Barthel 1986).

El Talatur se trata de un baile o ronda ritual, consiste en cantar a los cerros y al agua, junto con una seguidilla de brincos en uno y otro sentido de las manecillas del reloj, a imagen de las jerarquías y ubicación de los distintos cerros en el horizonte (Rodríguez 2003).

Tichy (1983), a partir de un trabajo previo (Mariscotti de Görlitz 1978), sugería la posibilidad de un sistema de líneas, a manera de ceques, proyectadas desde Socaire hacia los cerros de la región que coincidían con la posición del Sol para los solsticios y equinoccios en el horizonte.10 Al respecto, Reinhard (1983) entrega sugerentes datos de sitios ceremoniales prehispánicos (¿incaicos?) en gran parte de los cerros invocados desde Socaire (Figura 5).

\footnotetext{
9 Zuidema (1990: 639) plantea que tanto en Socaire como en el Cusco, la primera dirección del sistema de ceques se orienta hacia un importante recurso de agua. De allí, la importancia de volcán Chiliques como el origen de las aguas del canal de riego, que además concentra las aguas de otros cerros de la región.

${ }^{10}$ ceque: 1) Sayhuani, sayhuacuni: amojonar tierras, hacer linderos. 2) Sayuac o cequec: deslindador. 3) Cequeni. gui o sayuani gui: deslindar heredad o dividirla con lindero. 4) Ceqque: raya, línea, término. 5) Ceqqueni: rayar, linear, deslindar. 6) Allpa: La tierra de labor y el suelo. 7) Allpa tupuk apu, o cequek apu: medidor o repartidor de tierras (González Holguín 1952; Sanhueza 2004: 493; Santo Tomás 1951 [1560]).
} 


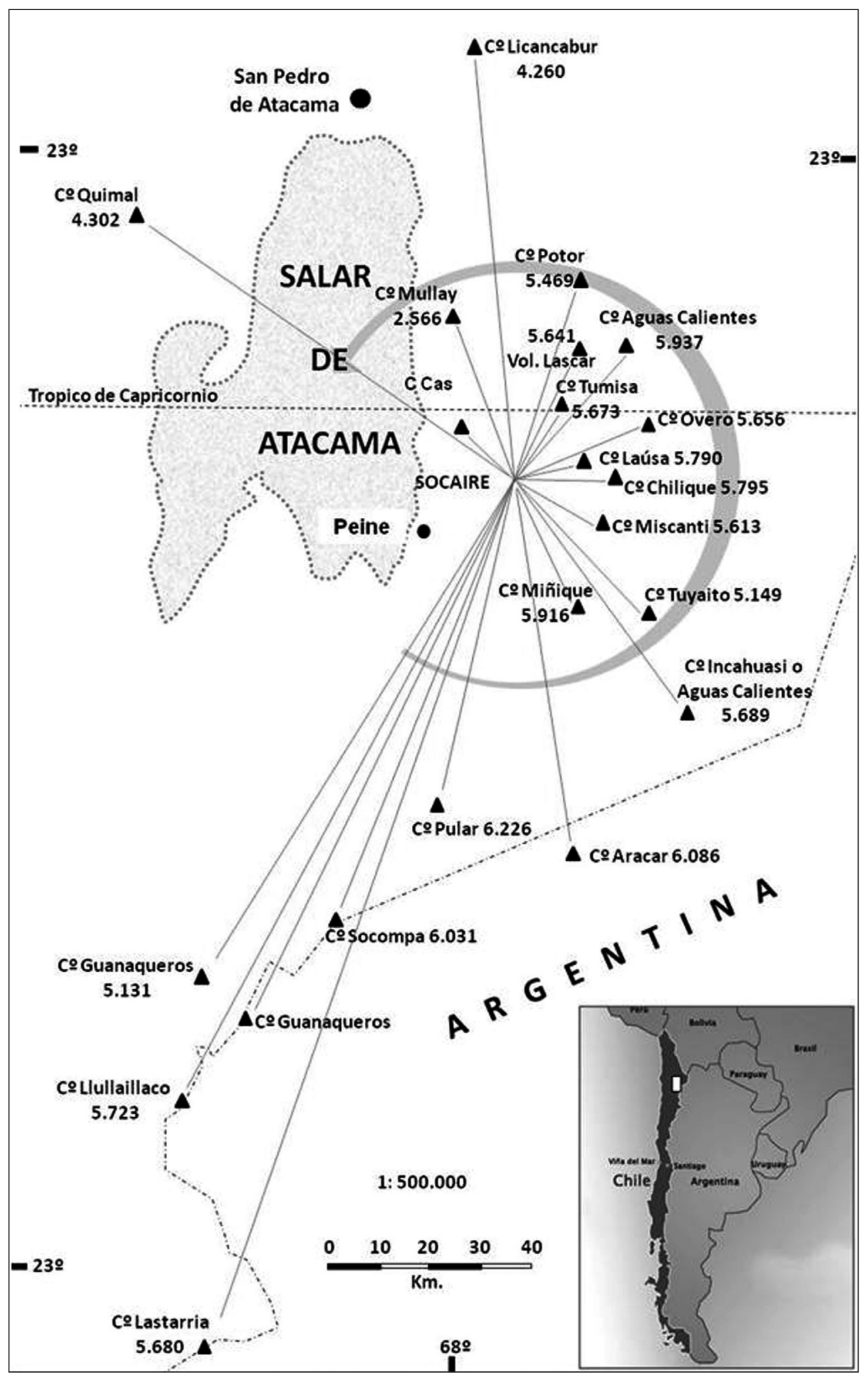

Figura 5. Sistema de ceques (Mariscotti de Görlitz 1978). 


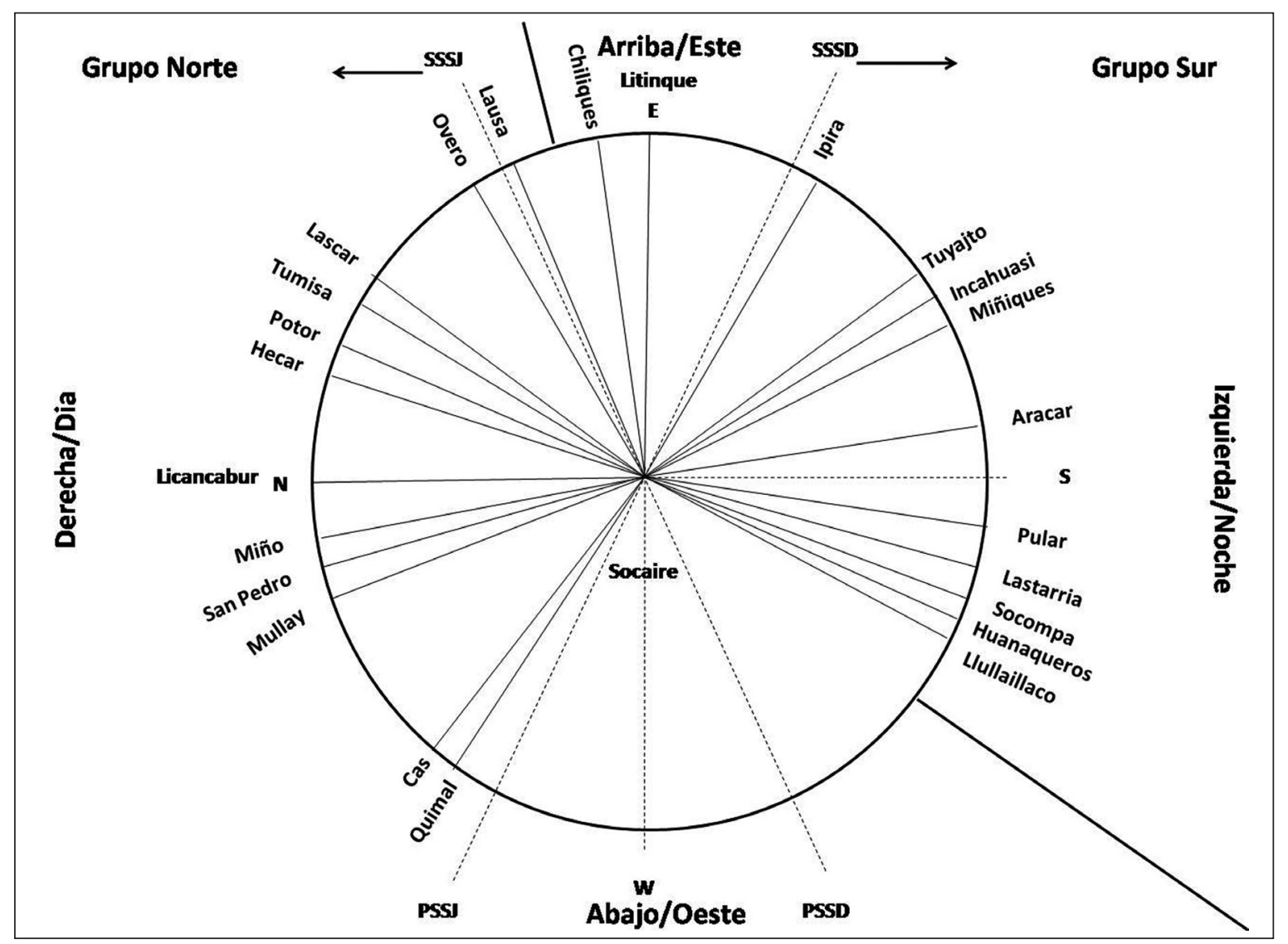

Figura 6. Sistema de ceques (Moyano 2010).

El análisis de las categorías espacio-temporales, entre los cerros del grupo norte y sur, reconocidas por los cantales de Socaire (Moyano 2011), genera un esquema que incluye las categorías de arriba/naciente, abajo/poniente, izquierda/noche y derecha/día, o sistema de orientación con respecto al Sol y a los cerros (Figura 6).

Con respecto al régimen del riego, Valenzuela (2000: 59) plantea la existencia de un sistema de turnos administrados por un alcalde de aguas. Éste dispone un orden correlativo comenzando primeramente en el sector El Tapial donde el agua se queda detenida durante dos días y una noche, para luego ser enviada al sector Peñaloza durante tres días, posteriormente a San Francisco donde demora en regar aproximadamente tres a cuatro días. Cuando en este sector se concluye el regadío, el juez se encarga de repartir el riego sincrónicamente entre el sector Compañía y el sector Desierto y distribuirles el turno precisa- do, el que finalizado en dos jornadas, se dirigirá hacia el sector Negreros y Llanos para regar potreros de alfalfa. En seguida, el riego le corresponderá a San Bartolo para proseguir con los terrenos ubicados en el pueblo y concluir el riego en el sector Santa Rosa, cerrando el círculo del agua e iniciándolo nuevamente en El Tapial, es decir, siguiendo el sentido del movimiento del Sol en contra de las manecillas del reloj (este-norte-oeste-sur), según la tradición atacameña (Moyano 2010).

Finalmente, Zuidema (1989: 464-466) plantea similitudes entre las actividades realizadas en Socaire y la ceremonia de la Citua (mes lunar de septiembre) en Cusco. Primero, por la invocación de ciertas montañas como proveedoras de agua. Segundo, por la existencia de líneas visuales y de una piedra que simboliza al volcán Chiliques que concentra las lluvias de los demás cerros. Tercero, por la relación directa entre la división de la tierra, las divisio- 
nes sociales y los tramos del canal de irrigación. Y cuarto, por la relación mítica de las montañas como lugares de nacimiento del agua, los antepasados y el orden social. De ahí, se plantea la existencia de un sistema de ceques y calendario de horizonte integrado, con fines particularmente agrícolas en Socaire.

\section{* "Morar o vivir en el mundo"}

Desde una perspectiva construccionista, cada sociedad erige el mundo en el que vive a través de los sentidos, es decir, crea su propia cosmovisión o World view (punto de vista de las cosas). El "morar o vivir en el mundo" se define como el resultado del "estar-ahí" (Dasein) y de las intersubjetividades del ser humano con el mundo que le rodea (Iwaniszewski 2007, siguiendo a Heidegger 1999). Un producto de la acción y categorías sociales dadas por sentado, es decir, del ámbito de lo ontológico o del conocimiento de las cosas en sí.

En este trabajo, retomamos elementos del materialismo histórico de Kearney (1975), quien resalta determinados aspectos de las cosmovisiones. Éstos son los principios de: el sí mismo y el otro, relación, clasificación, causalidad, tiempo y espacio, que pudieran entenderse como universales e inherentes a la condición humana, pero con contenidos ciertamente distintos. A continuación, nos centraremos en los conceptos de tiempo y espacio como etnocategorías de análisis para nuestro caso de estudio.

Para Durkheim, el tiempo y el espacio son categorías sociales o representaciones colectivas. En otras palabras, “...ideas y sentimientos comunes que las generaciones se pasan una a otras", resultado de la sociedad en su conjunto y no de puras individualidades (Durkheim 1970 [1914]: 101, en Huici 2007: 11-14). Podríamos entenderlas entonces, como una especie de doxa, con sentido en la dinámica social propia que le dio origen. El espacio se reconoce como un punto de referencia para la elaboración de la representación colectiva, "...ocupado por la sociedad... que ha proporcionado la materia prima de categoría de espacio" (Durkheim 1982 [1912]: 409, en Huici 2007: 20-21). El tiempo, por otro lado, reflejaría el ritmo de la vida social, p.e. un sistema de calendario con la división del tiempo en días, semanas, meses y años (Durkheim 1982 [1912]: 9, en Huici 2007: 20-21).
El espacio y el tiempo no son medios neutros y homogéneos, independientes del desarrollo de la acción social. Se desarrollan dentro de medios heterogéneos y singulares, cuyas características se suceden en ritmos y ciclos determinados. Espacios y tiempos se relacionan con hechos humanos y fenómenos naturales, dentro del concepto de "lugar-instante" como lo define Soustelle (2004), cercano a la concepción andina de pacha.

En este contexto, nuestra arqueología del paisaje intenta conocer como los seres humanos visualizan, comprenden y manipulan el espacio y el tiempo. Como estas categorías afectan la percepción del sí mismo y del otro, dentro de una causalidad ritual determinada por aspectos concretos de la experiencia ligada a la veneración a las montañas. Se entiende entonces a la naturaleza como la prolongación de las relaciones sociales establecidas por los seres humanos, es decir, como una especie de animismo donde se le atribuye vida anímica y poderes a objetos del entorno, como astros, montañas, ríos, rocas, plantas, árboles, animales y otros. Donde las relaciones sociales con los seres no-humanos entran en el mismo nivel de complejidad, es decir, entre pares que infunden respeto en los mismos y viceversa (Descola 1998, Hornborg 2006). ${ }^{11}$

Iwaniszewski (2007: 16) afirma que el paisaje es el resultado de la conceptualización que cada sociedad tiene del mundo, en otras palabras, un proceso de "vivir en el mundo", que no jerarquiza de manera implícita o explícita, los aspectos físicos y simbólicos del mismo. Para Heidegger, el morar o residir está implícito en la relación de los seres humanos con las cosas que le rodean, es decir, una propiedad quinésica y sensual. Mientras que para Merleau-Ponty, desde una postura intermedia entre el empirismo objetivo y el idealismo cognitivo, la percepción es una acción física y química de parte de los órganos de la percepción (Tilley 1994: 13).

Desde esta postura, se asume al cuerpo humano como punto de partida para el conocimiento del mundo, donde

${ }^{11}$ Por ejemplo, entre los achuar de la Amazonia ecuatorial se asume que la mayor parte de las plantas y animales poseen un alma (wakan), similar a la de los seres humanos, es decir, reflexiva y con intencionalidad, pudiendo inclusive experimentar distintos tipos de emociones (Descola 1998: 221). 
objeto y sujeto, naturaleza y conciencia, están inmersas en un todo dialectico definido como "morar en el mundo", donde la acción social siempre estará en referencia "a". En el caso de Socaire, en referencia "a" distintos elementos de la topografía, identificados como propiciadores de los fenómenos meteorológicos y el ganado "los cerros o Tata Maikus" (Josefa Cruz, com. pers. 2009).

Siguiendo a Tilley (1994: 14-15, 26), definimos "lugar" como aquellos centros de significado humano, puntos de referencia, valores y reservorios de la memoria, p.e. el centro ceremonial de Socaire. Éste provee la seguridad ontológica necesaria a cada individuo, un punto de referencia "a" dentro de lo que se ha definido como "morar o vivir en el mundo".

Como parte de la experiencia sensorial, toman importancia las narrativas míticas asociadas al paisaje. Se entiende a éste como parte de un conocimiento "sensorial", resultado de la memoria colectiva que se impregna de los sentidos de pertenencia y no-pertenencia, similitud y diferencia, lo visible y no-visible, el yo y el otro, dentro de lo que Tilley (1994: 31) ha definido como "senderos", o lugares que conectan distintos lugares, a manera de ceques o líneas proyectadas en el paisaje.

Otra categoría es la del horizonte, definido por Iwaniszewski (2001: 222-223) como el conjunto de rasgos que pudieron constituir marcadores calendáricos, particularmente para el disco solar, cuyo valor sociocultural se enmarcaba dentro de la observación e interpretación del cielo (Iwaniszewski 2009). A ésta, podríamos agregar la de los fenómenos cenitales, es decir, aquellos pases del Sol, la Luna y determinadas constelaciones por sobre la perpendicular de las cabezas del observador, que, en el caso de la astronomía incaica, estaba mediada por el sistema de ceques o conjunto de 41 (42) direcciones (líneas de visión) que organizaban 328 huacas o lugares sagrados (piedras, manantiales, cerros y/o construcciones) en la topografía del Cusco.

El sistema de ceques constituye un buen ejemplo de la utilización del horizonte y los pases cenitales, en función de categorías analíticas de parentesco, jerarquías políticas, condiciones del tributo y fechas calendáricas, dentro de un sistema luni-solar, dual, ternario, cuadripartito, quinquepartito y decimal, que regia las relaciones endo y exogámicas entre el Hanan (arriba) y el Hurin (abajo) en Cusco (Zuidema 1995, 2011).

La experiencia de "morar en el mundo" dependerá del punto de vista que adoptemos con respecto a estos lugares, senderos, horizontes y cenit. En otras palabras, una experiencia multisensorial que incluye el arte de caminar, oler, escuchar y sentir el paisaje (Tilley 2008: 272), donde no existirá la diferencia tácita entre naturaleza y cultura, ya que metodológicamente siempre se toma en cuenta un lugar o sendero con respecto a otro, y también con respecto a lugares naturales sin modificación cultural. Creemos, al igual que Bradley (2000), en que es posible hacer entonces una arqueología de los lugares "naturales". En el caso andino, bajo el concepto de huaca como elemento distintivo de un paisaje socialmente construido y adaptado a las necesidades del ser humano.

En Socaire, la invocación de las montañas durante la ceremonia de petición de lluvias adquiere un sentido práctico y ritual, no solo en el momento mismo del rito, sino también en la previa con la limpia del canal y las ofrendas de aloja y plumas de flamenco. Un reconocimiento tácito de la topografía, donde la acción de comer y beber con las piedras del centro ceremonial, refuerza cíclicamente las relaciones que pudieran existir entre los miembros de un grupo familiar y un determinado cerro. Allí, el centro ceremonial representaría el útero femenino como lugar de origen de las aguas para la siembra y el ganado. Una representación a escala del horizonte -con los cerros (como parte masculina)-, y su complemento - con el canal y la tierra (parte femenina)-, dentro de lo que podríamos llamar el "morar o vivir en el mundo" de los socaireños.

En síntesis, entendemos al paisaje como un conjunto de escenarios, momentos (la fiesta) y lugares nombrados, reconocidos socialmente y unidos por senderos -en nuestro caso líneas de visión o ceques- reconocidos etnográficamente como "líneas de convidos a los cerros" (Diego Cruz, com. pers. 2009). Este paisaje, será el resultado de distintas categorías del "vivir o morar en el mundo", en otras palabras, la experiencia sensorial y narrativa cuya base estará en la relación misma que establecen los seres humanos con su entorno, a través de las distintas prácticas culturales regidas por el calendario de fiestas. 


\section{* El tawantinsuyu en atacama}

El desarrollo y expansión del Tawantinsuyu viene a ser la última etapa de una larga y milenaria historia del mundo andino (Hidalgo 2001). La discusión teórica sobre la expansión del Tawantinsuyu se ha basado en el tipo de dominación, sea ésta directa o indirecta (Llagostera 1976), basado en el modelo de Murra (1972).

Para el caso particular de Atacama, se plantea un dominio directo "a través del manejo de los ancestrales principios andinos de organización socioeconómica. Así, la reciprocidad y redistribución fueron convertidas en mecanismos de apropiación y dominio a través del potencial simbólico de una materialidad arqueológicamente perceptible" (Uribe 2004: 317). En este contexto, la presencia de tambos, canchas, collcas, ushnus, santuarios de altura, material cerámico (aríbalos), tejidos, miniaturas en metal y arte rupestre, denota una violencia manifiesta en el control de la producción de bienes y servicios, así como política y económica, que instauró el Tawantinsuyu con fechas cercanas al 1450 DC (Uribe 2004: 313).

Esta vasta materialidad estaría representada, en parte, por los adoratorios de altura, componentes claves dentro de la conquista ideológica de los territorios anexados al Tawantinsuyu (Schobinger 2001). Para lograr este objetivo, los inkas ocuparían el norte de Chile "disfrazado con ropajes de los pueblos altiplánicos sometidos a su dominio" (Aldunate 2001: 20), es decir, aprovechando las antiguas relaciones que existían entre los pueblos altiplánicos y los grupos locales para afianzar una influencia y un dominio que se puede entender como directo.

Siguiendo a Bittman y colaboradores (1978), Uribe (2000: 69) plantea que el dominio inka en el salar de Atacama fue "oblicuo", es decir, con una influencia no directamente llegada desde el Cusco, sino de los distintos centros administrativos del altiplano, donde la mediación entre el Tawantinsuyu y las poblaciones locales habría tenido lugar en espacios de alta significación simbólica, como son las montañas. Así, el Tawantinsuyu, al instalarse sobre antiguos adoratorios locales, resignificó y reconstruyó espacios, aplicando nuevos cánones a expresiones de antigua data en el mundo andino (Aldunate 2001).

Arqueológicamente, esto se ve reflejado en dos aspectos dialécticamente relacionados, como son el mundo espiritual con el mundo cotidiano. El mundo religioso/ espiritual, representado en los adoratorios de altura en los volcanes Licancabur, Juriques, Lejía, Chiliques, Miñiques, Miscanti y Quimal, entre otros, denota en parte una relación más cercana con la zona nuclear del imperio, con alfarería, metales y lapidaria de rasgos propiamente cuzqueños (Beorchia 1985, 2001; Le Paige 1978).

Por otro lado, el mundo cotidiano representado en los sitios habitacionales presenta una situación algo diferente, pues en muchas ocasiones la cerámica local es la más abundante. De esta forma, mientras en los adoratorios de altura se presenta una realidad basada en el esquema incaico, en los sitios de vivienda se abren los espacios para los discursos locales (Troncoso 2001).

El Tawantinsuyu produjo cambios profundos, especialmente en la ideología atacameña, la cual pasa de ser una religión del tipo chamánica, con especialistas extáticos gracias al uso de sustancias psicoactivas, a una religión de tipo estatal centralizada, basada en el uso de la hoja de coca y el culto solar (Aldunate 2001). Los especialistas (chamanes) dejan su lugar a la montaña, relacionada más con la fertilidad y la lluvia (Moseley 1992), donde el Inka como hijo del Sol tenía el lugar central. Este vínculo entre montaña y fertilidad pudo haber sido uno de los principales móviles ideológicos para la construcción de adoratorios de altura por parte del Tawantinsuyu (Beorchia 1985; Reinhard 1983).

Por estas razones, se asume que en los adoratorios de altura se hubieran realizado actividades repetitivas y claramente normadas por el Estado en expansión, que incluyeron la llegada de ofrendas de todas partes del Tawantinsuyu al Cusco, como victimas sacrificiales, y que después fueron redistribuidas mediante desfiles y procesiones hacia su destino final en los confines del Imperio por medio de ceques (Duviols 1976). En el caso del desierto de Atacama, las expansiones inka fueron claramente mediadas por la necesidad del Estado en acceder a los distintos recursos mineros de la región (Núñez 1999).

Sin embargo, no descartamos la posibilidad de que en momentos de dominio incaico se mantuvieran presentes elementos de la ritualidad atacameña en algunos cerros de la región. Al respecto, Ibacache (2007) plantea como hipótesis la posibilidad cierta de que grupos 
locales participaran abiertamente en los adoratorios de Chiliques, Licancabur y Quimal, a partir de la evidencia cerámica, donde la presencia cusqueña fue más bien un elemento fundacional, reflejada en distintos tipos de ofrendas, sacrificios o arquitectura, que luego es reutilizada y seguramente resignificada por peregrinaciones locales periódicas o semi-periódicas a la montaña.

Esta hipótesis claramente introduce nuevos ápices a las nociones de expansión, dominación e integración (Uribe 2004), entre el Tawantinsuyu y los grupos locales, asumiendo más bien una mirada bidireccional en las relaciones de control y dominación propias de un proceso expansivo como el inka (Ceruti 1999). Desde este punto de vista, siguiendo a Uribe (2004: 321), se podría hablar entonces de una "complejidad atacameña" en el período Tardío, que integró los desarrollos regionales agrícolas y caravaneros previos a la llegada del inka. El desarrollo de dicha complejidad fue promovido por una dinámica "supra comunitaria", con características similares a las observadas en el Noroeste de Argentina, donde se experimentaron relaciones de producción, complementariedad y reciprocidad (social, económica, política y religiosa) entre el Tawantinsuyu y las autoridades locales. En el caso del salar de Atacama, este proceso refleja una herramienta política utilizada por los inkas que fue impulsado por las diferencias sociales internas de los grupos indígenas locales (Uribe y Adán 2004).

Por consiguiente, toman gran importancia los aspectos religiosos vinculados al calendario de fiestas y actividades, con la incorporación de todos aquellos elementos potencialmente sagrados (huacas) al imaginario social de los habitantes del salar de Atacama. A continuación, exponemos algunos de los aspectos preliminares del reconocimiento arqueológico de superficie en el volcán Chiliques, así como sus implicancias sociales para los actuales habitantes del poblado de Socaire.

\section{* Resultados preliminares}

En diciembre de 2008, se pudo constatar la existencia de evidencias prehispánicas en la ruta de ascenso al volcán Chiliques (5778 m.s.n.m.), ya referidas por otros autores (Agüero 2008 Ms; Beorchia 1985; Reinhard 1983, 1993

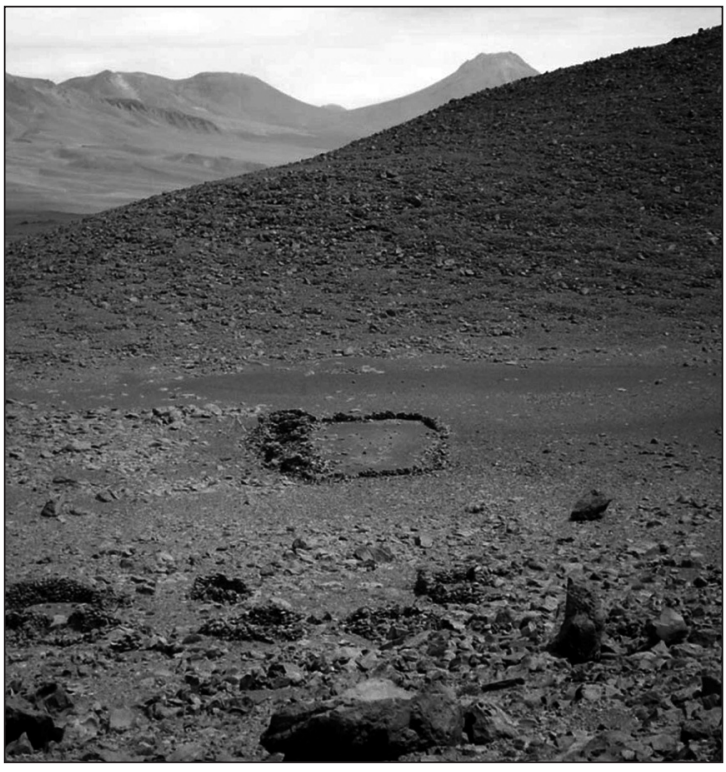

Figura 7. Vista del tambo Chiliques (4565 m.s.n.m.).

Ms). Para ello, se siguió la ruta prehispánica que va desde el sector denominado como Meseta del Inka, en dirección norte-sur.

El sector tambo Chiliques (UTM 19K 0632407 E, 7394612 N, 4565 m.s.n.m.) corresponde a una sección plana ubicada junto a la quebrada que une la Meseta del Inka con la ladera noreste del volcán, al lado sur del camino prehispánico. La zona no presenta cursos de agua permanente ni vegetación, y se ve dominada por un paisaje eminentemente árido y al resguardo del viento (Figura 7).

El tambo corresponde a un espacio trapezoidal con orientación norte-sur, constituido por un Recinto Perimetral Compuesto (RPC) con una plaza en el sector este (muro simple) y cinco recintos adosados al muro oeste (muros dobles con relleno) de distintas dimensiones y vanos orientados en dirección este. El espacio total del RPC tiene las siguientes dimensiones: $20,5 \mathrm{~m}$ (muro oeste), 14,3 m (muro norte), $20 \mathrm{~m}$ (muro este) y $10 \mathrm{~m}$ (muro sur). La altura de los muros varía entre los $50 \mathrm{~cm}$ en la parte de la plaza y $1,5 \mathrm{~m}$ en la parte de los recintos (Figura 8). A diferencia del dibujo realizado por Reinhard (Beorchia 1985, Sección Documental, Zona C), con muros rectos y formas rectangulares, el tambo presenta muros en parte curvos y esquinas redondeadas 


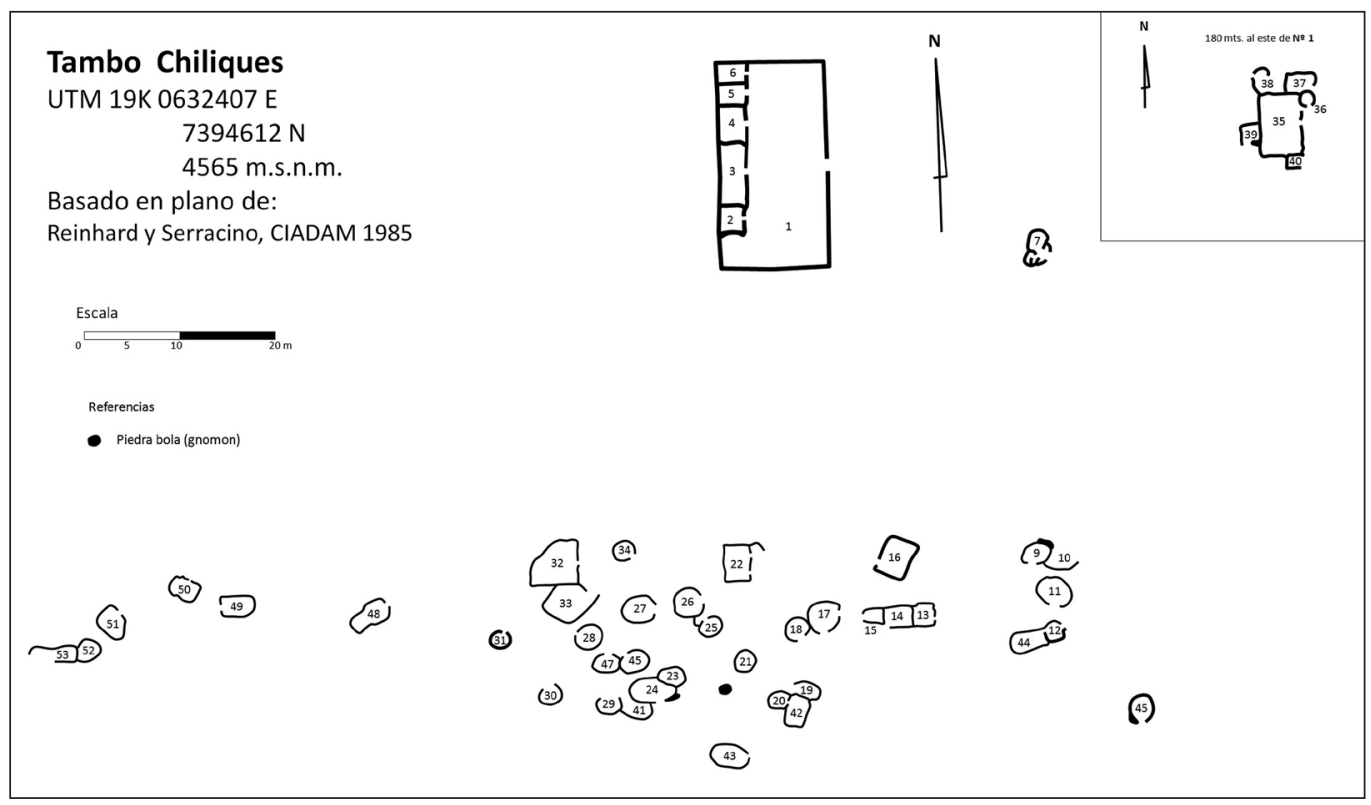

Figura 8. Plano del tambo Chiliques (Reinhard 1983).

con una orientación del muro oeste de $349^{\circ} \mathrm{O} 2^{\prime}$ con respecto al norte astronómico.

De acuerdo con Reinhard (1993 Ms), el tambo Chiliques, al igual que las ruinas del volcán Licancabur (Le Paige 1978), constituiría el espacio para un grupo de mayor estatus social, quienes se ubicarían en la plaza o en los recintos inmediatos a ésta, formando parte de los llamados "especialistas rituales". El resto de la población habría ocupado las demás estructuras de la ladera, algunas de las cuales pudieron también servir como depósitos de alimento. Dentro de la arquitectura general, destácase el Recinto 5 (Beorchia 1985), que presenta un vano y dintel de altura 1,38 $\mathrm{m}$ y $60 \mathrm{~cm}$ de ancho (Figura 9). Al interior del recinto se observan restos de un poyo o estructura rectangular adosada al muro norte.

Al interior de la plaza central, se encuentra abundante material cerámico fragmentado, correspondiente a grandes vasijas o contenedores de tipo Ayquina (Varinia Varela, com. pers. 2009). El sector no presenta evidencias saqueo.

Otro grupo de estructuras $(35,37,38,39$ y 40) (UTM ${ }_{19} \mathrm{~K} 0632598 \mathrm{E}, 7394584 \mathrm{~N}, 4569$ m.s.n.m.) se localizan

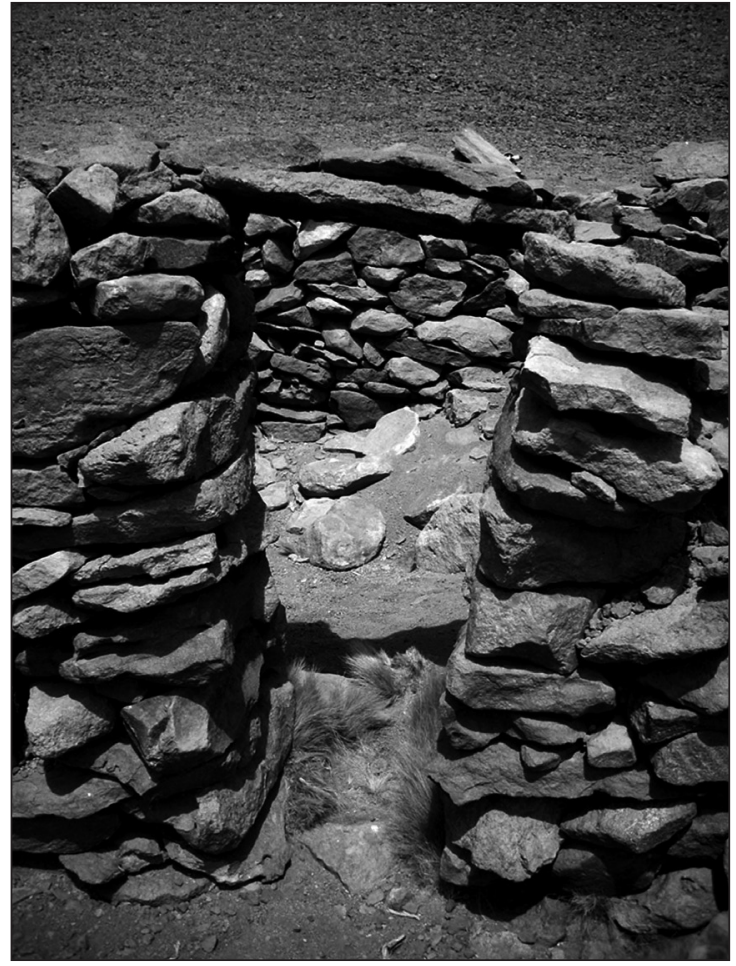

Figura 9. Recinto 5, tambo Chiliques. 
junto al camino, a $30 \mathrm{~m}$ del tambo en dirección este. Estas estructuras parecen haber tenido su función principal en relación a la ruta de ascenso, dada sus características arquitectónicas (muros más rectangulares, altos y dobles con relleno) y ubicación en el espacio (visibles desde la ruta de ascenso).

A poca distancia del tambo, en dirección sur, se localiza un grupo de casi 40 estructuras circulares y rectangulares en la ladera norte del volcán Chiliques. Las estructuras no presentan un patrón regular, pero parecen haber sido construidas en función del tambo. En general, presentan muros no muy altos, de construcción en hilera simple, aprovechando la pendiente y rocas de la ladera del cerro.

De las estructuras mencionadas, se destacan la 7 y la 8 en las inmediaciones del tambo (20 m en dirección este) (UTM 19K 0632438 E, 7394611 N), debido a la presencia de cerámica monocroma, de pasta negra con mica, paredes lisas y escobillado.

En la estructura 44, de muros simples y dimensiones 3,7 $\mathrm{x}$ 2,5 m (UTM 19K 0632441 E, 7394574 N, 4558 m.s.n.m.), se identificaron tipos cerámicos locales, como el Turi Rojo Alisado, de amplia distribución en la zona atacameña durante los períodos Intermedio Tardío (1000-1400 DC) (Schiappacasse et al. 1989) y Tardío (1450-1530 DC). En la estructura 26 (UTM 19K 0632413 E, 7394565 N, 4565 m.s.n.m.), se encontró fragmentos de cerámica decorada, en los cuales se destaca un posible fragmento del tipo San Miguel Tardío, con su variedad decorada en el cuello (siglo XIII y XIV), con expresiones tardías paralelas al tipo Pocoma Gentilar (siglo XIV y XV). Sin embargo, su forma (parte de un plato) podría sugerir un origen sureño (Varinia Varela, com. pers. 2009), posiblemente diaguita-inka (valle del Copiapó, El Salvador).

En la estructura 22 (UTM 19K $0632411 \mathrm{E}, 7394571 \mathrm{~N}$, 4565 m.s.n.m.), ubicada a $30 \mathrm{~m}$ del tambo en dirección sur, además de cerámica engobada roja Tardía (hallada fuera de la construcción en sus lados sur y suroeste), se encontró un posible aríbalo inka local, además de restos malacológicos posiblemente de almeja. Cabe destacar que esta estructura es una de las mejores conservadas, tiene muros de 3,4 x 5,4 m, con técnica de muro en piedra canteada sin relleno y un vano de acceso trapezoidal en la equina noreste, de $60 \mathrm{~cm}$ de ancho y acimut de $86^{\circ}$ (brújula magnética). ${ }^{12}$ En la estructura 17 (UTM $19 \mathrm{~K}$ 0632420 E, 7394560 N, 4572 m.s.n.m.), se encontró cerámica del tipo Ayquina, descrito por Uribe y Carrasco (1999: 56) como platos clásicos del período Tardío con un tratamiento pulido en superficie, ca. 1200-1450 DC Finalmente, se encontró cerámica roja pulido y café alisado (cuerpos y bases) en la estructura 27 (dimensiones 4,7 X 4 m) (UTM 19K 0632397 E, 7394558 N, 4562 m.s.n.m.) y algunos fragmentos monocromos y un borde pulido en las cercanías del conjunto de estructuras 13, 14, 15 y 16 (UTM 19 K 0632427 E, 7394565 N, 4567 m.s.n.m.).

En lo referente al material lítico, se pueden identificar distintos tipos de lascas secundarias de basalto en la estructura 45, dimensiones $3,4 \times 3,9 \mathrm{~m}$, vano de $40 \mathrm{~cm}$ (UTM 19 K 0632454 E, 7394558 N, 4571 m.s.n.m.), distante del conjunto central, en dirección sureste, así como en la estructura 43, dimensiones 4,3 × 2,8 m (UTM 19K 0632422 E, 7394545 N, 4572 m.s.n.m.). Lascas de andesita fueron encontradas en la estructura 34, muro simple, 3 × 2,5 m (UTM 19K 0632398 E, 7394575 N, 4561 m.s.n.m.).

Cabe destacar la existencia de un monolito natural, ubicado en un sector central de la estructuras de la ladera norte de Chiliques, que desde un punto de vista simbólico podría también estar representando una huaca, y desde la perspectiva astronómica un posible gnomon, al no proyectar sombra para los días cercanos al solsticio de diciembre (inicio del verano en el hemisferio sur), por efecto de la latitud geográfica.

La ruta prehispánica iníciase cerca de la cota 4475 m.s.n.m. (UTM 19K 0632261 E, 7395459 N) y se desarrolla a media ladera, en el lado oriente de la quebrada que corre de sur a norte y que confluye al anfiteatro natural donde se concentran las estructuras circulares y el tambo (ver Figura 3). La técnica de construcción fue por despeje simple, a excepción de tramos cercanos a la cumbre donde existen pequeños aterrazados y un zigzag marcado de piedras.

Desde el campamento alto, ubicado a más de 4800 m.s.n.m., se inicia la marcha hacia la cumbre por la ladera noreste del volcán (ver Figura 3). En la ruta de ascenso, se identificó un conjunto de estructuras junto a un tramo de

\footnotetext{
${ }^{12}$ Con una declinación magnética de $4^{\circ} 13^{\prime} \mathrm{W}$ (23/12/08). http: // recursos.gabrielortiz.com/index.asp
} 


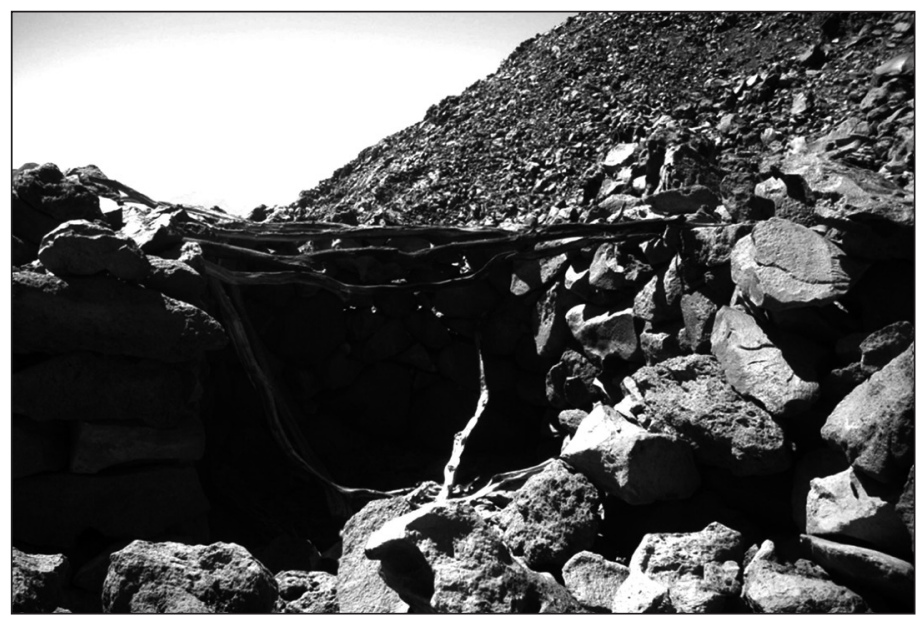

Figura 10. Estructura techada (5571 m.s.n.m.).

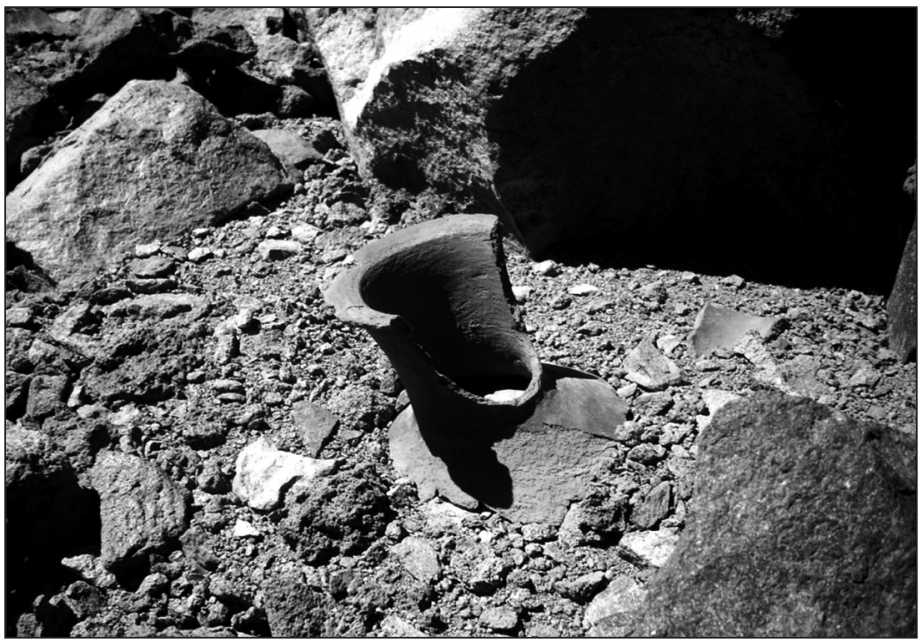

Figura 11. Cuello aríbalo (5565 m.s.n.m.).

camino en zigzag, dentro de las cuales se destaca un recinto construido en técnica de muro doble con relleno (UTM $19 \mathrm{~K} 0632811 \mathrm{E}, 7392403 \mathrm{~N}, 5571$ m.s.n.m.). Las dimensiones de la estructura son de 4 × $6 \mathrm{~m}$, y 1,5 $\mathrm{m}$ de altura, presenta parte de sus muros colapsados y mantiene en parte la estructura del techo (en algarrobo o chañar) (Figura 10).

En la ruta de zigzag (de o,7 a $1 \mathrm{~m}$ de ancho), es posible también encontrar restos de madera tirada en el camino, posiblemente de algarrobo (Prosopis sp.), entre los 5626 m.s.n.m. (UTM 19K 0632745 E, 7392314 N) y los 5641 m.s.n.m. (UTM 19K 0632742 E, 7392246 N). En las cercanías también se destaca la presencia de un cuello y borde de aríbalo (inka local), ${ }^{13}$ con engobe exterior (UTM $19 \mathrm{~K} 0632814$ E, 7392410 N, 5565 m.s.n.m.) (Figura 11).

\footnotetext{
13 Siguiendo a Uribe y Carrasco (1999) y Uribe (2004), podríamos pensar que este tipo de artefacto estaría formando parte de los aspectos locales de la presencia inka en la región, en particular de aquellas nociones ligadas con las actividades redistributivas, en este caso, el almacenamiento de líquido (posiblemente chicha) destinado a la ofrenda dentro de las actividades rituales llevadas a cabo por los curacas locales.
} 


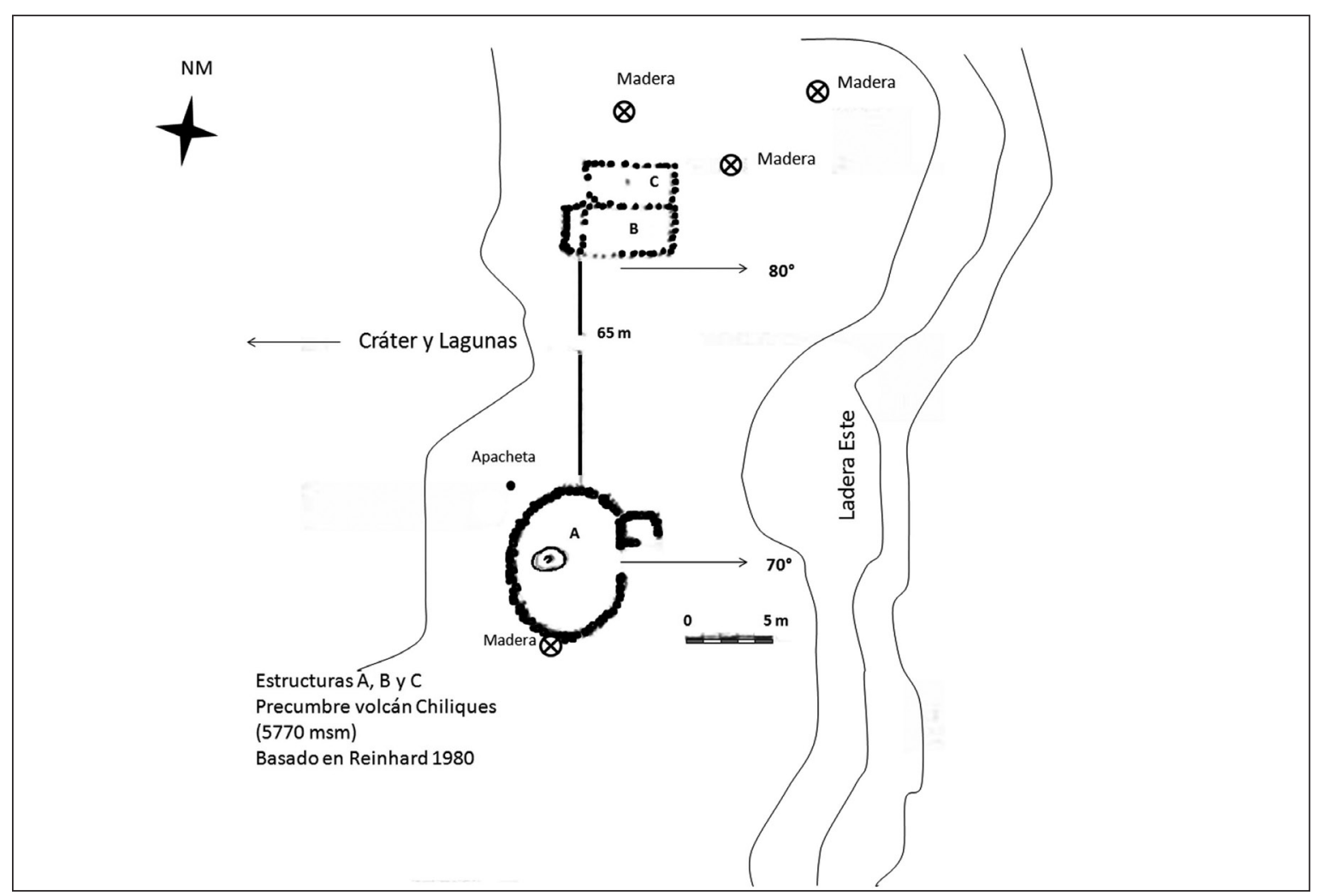

Figura 12. Estructuras precumbre en el volcán Chiliques (Reinhard 1983).

En las inmediaciones de la cumbre norte, se notificó la existencia de al menos seis estructuras (tipo recintos) entre los 5728 m.s.n.m. (UTM 19K 0632662 E, 7392202 N), y los 5735 m.s.n.m. (UTM 19K 0632632 E, 7392191 N). Estas pircas se encuentran construidas en técnica de muro simple, aprovechando los espacios entre la ladera y pendiente. No se observa material arqueológico en superficie. Una razón para la construcción de los recintos en una zona cercana a la cumbre puede ser evitar los fuertes vientos que soplan después del medio día.

En la cumbre del volcán Chiliques, se dio cuenta de las estructuras A, B y C descritas por Reinhard (Beorchia 1985: 71-73) (Figura 12). La primera se ubica sobre un espolón rocoso en el sector este del edificio volcánico. Éste se compone de un cráter doble, donde existen hoy dos lagunas medianamente profundas (Figuras 13 y 14), separadas por un sector plano, sin estructuras o material cultural. Las plataformas $\mathrm{B}$ y $\mathrm{C}$ se localizan hacia el norte, en la zona más amplia del sector.
La estructura A (UTM 19K $0632630 \mathrm{E}, 7392027 \mathrm{~N}$, 5770 m.s.n.m.) corresponde a una estructura elíptica de muro simple, orientado al este (ancho $25 \mathrm{~cm}$ ), tiene una piedra central tipo gnomon en su parte centraloeste (Figura 15). En superficie no se observa material cultural, solo madera en la pared SE (1 $\mathrm{m}$ de largo). La roca gnomon y posible huaca tiene 1,6 x 1,4 $\mathrm{m}$ y $75 \mathrm{~cm}$ de alto. Desde el lugar, se tiene la vista de los lados norte, este y sur del horizonte. La cresta de la cumbre principal al oeste tapa la vista hacia el poblado de Socaire. Se destaca aquí la estructura semi rectangular ubicada junto al vano de acceso este, una posible habitación para especialistas rituales. El lugar no se encuentra excavado ni intervenido, por cuanto presenta excelentes condiciones de conservación para futuras prospecciones y pozos de sondeo.

Por su parte, las plataformas B y C (UTM 19K 0632611 E, 7392096 N, 5760 m.s.n.m.), corresponden a dos plataformas construidas a baja altura, unidas por uno de 


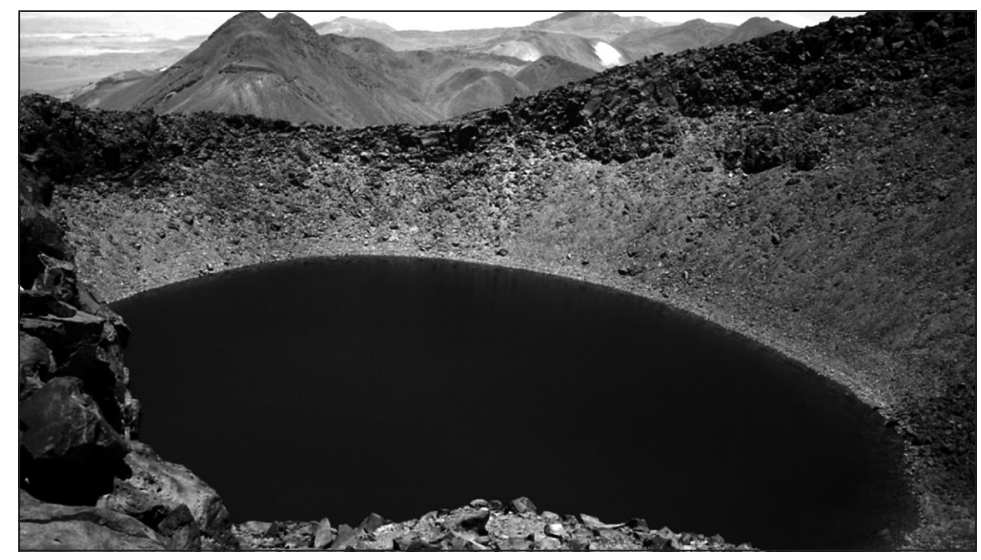

Figura 13. Laguna sur en la cumbre del volcán Chiliques.

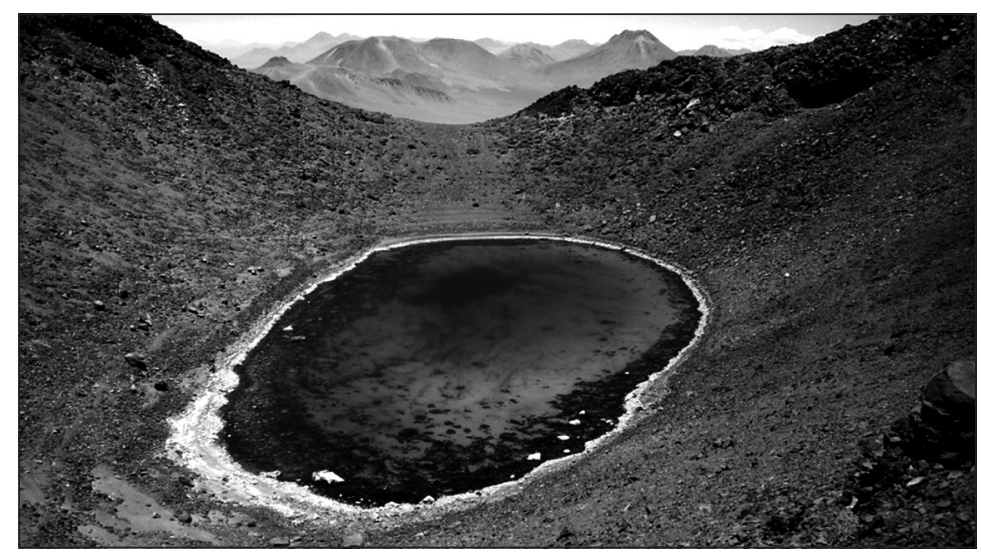

Figura 14. Laguna norte en la cumbre del volcán Chiliques.

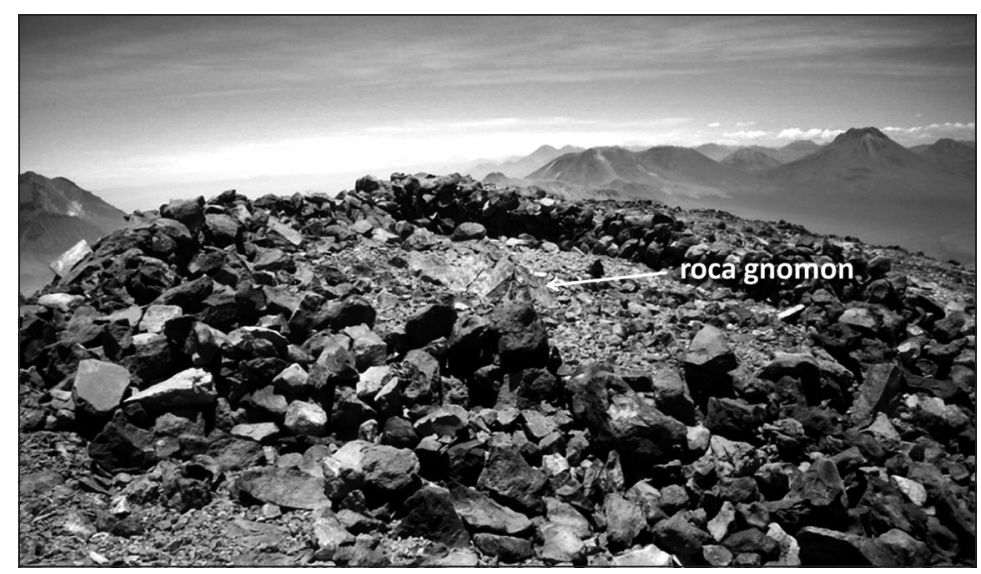

Figura 15. Estructura A, precumbre del volcán Chiliques (5770 m.s.n.m.). 


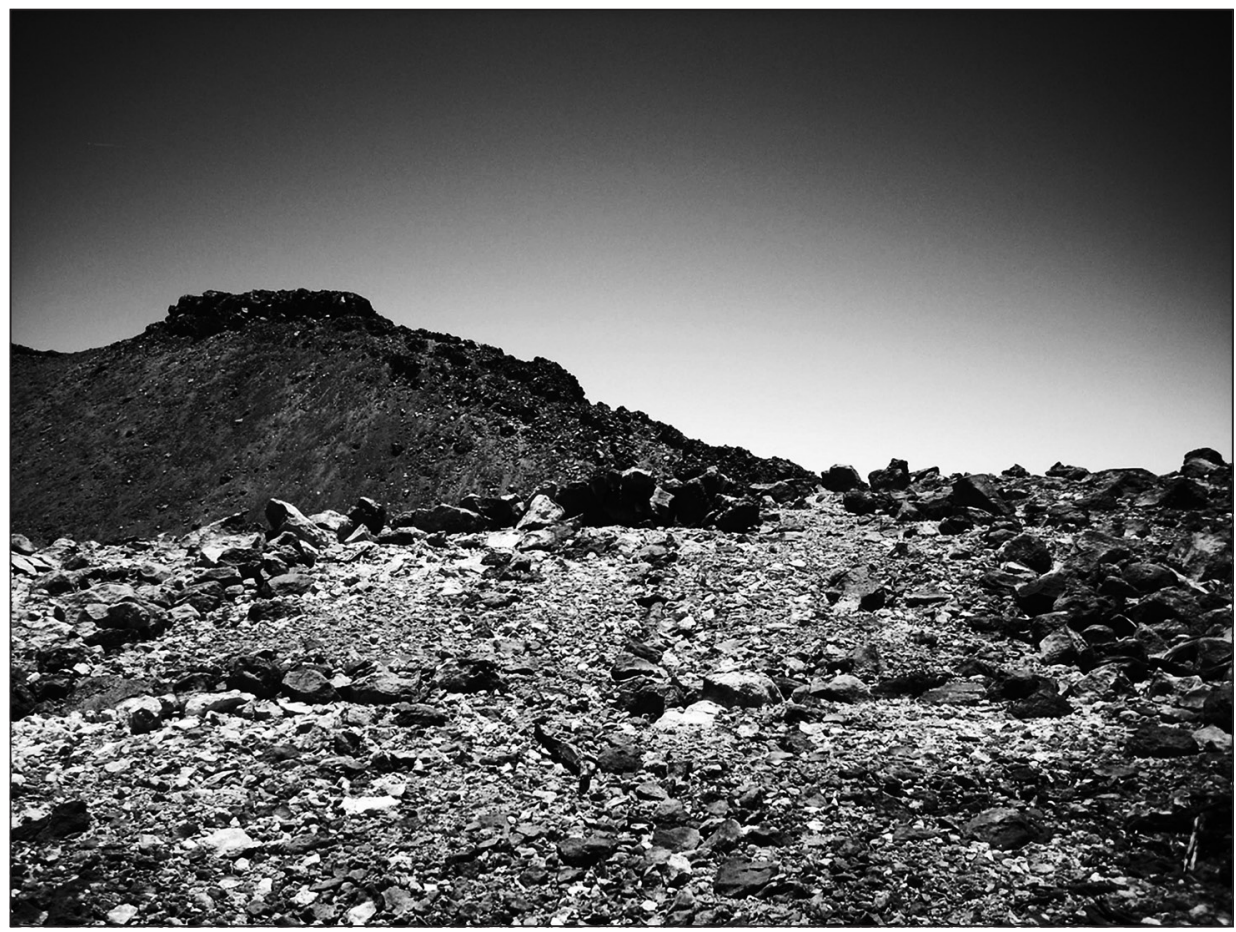

Figura 16. Estructuras B y C, precumbre del volcán Chiliques (5760 m.s.n.m.).

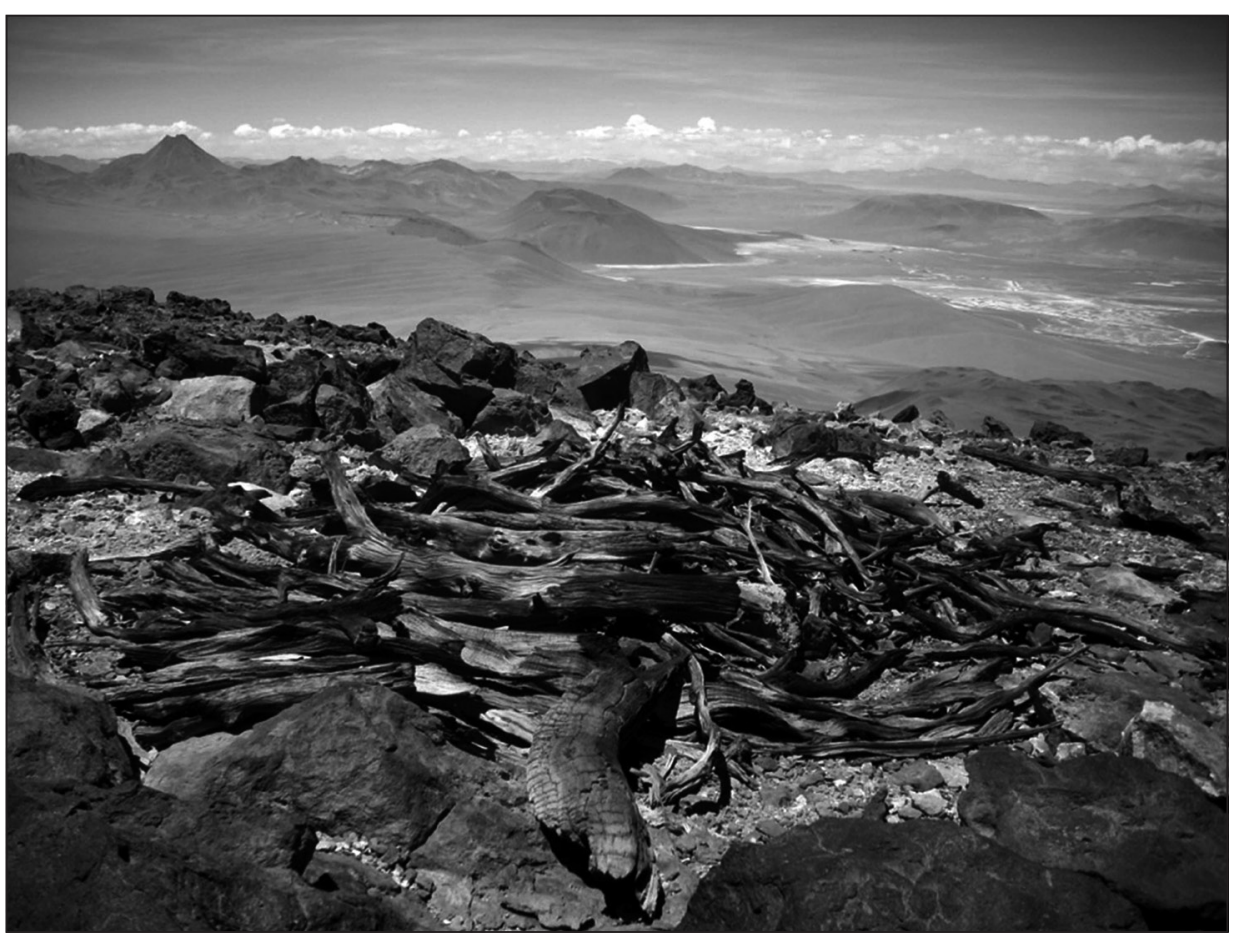

Figura 17. Madera encontrada en la precumbre del volcán Chiliques, vista al noreste (5761 m.s.n.m.). 
sus muros, en la zona más amplia y plana de la cresta del cono volcánico (Figura 16).

Desde este lugar se tiene una excelente vista del lado norte de la montaña, así como de la ruta de ascenso por la ladera noreste. Ambas fueron construidas en técnica de muro simple (10 cm alto), tienen una orientación en el eje mayor de 80 grados (brújula magnética) ${ }^{14}$ y se ubican en la parte más amplia y plana del cráter volcánico. Ambas plataformas podrían haber recibido a un número importante de asistentes, en comparación con el sector de la estructura A. En las cercanías, se puede observar abundante madera tirada por todos lados, en parte quemada y apilada. La pila principal (algarrobo o chañar) se ubica dispersa en un radio de $60 \mathrm{~m}$, a 5761 m.s.n.m. (UTM 19K 0632618 E, 7392103 N). Desde este sector de la cumbre, se tiene una excelente vista del volcán Pili y del salar de Aguas Calientes (Figura 17).

Desconocemos si existen estructuras en las riveras de las lagunas identificadas en el cráter volcánico. Entre ambas lagunas, hay una zona plana donde existen formas "naturales" sugerentes de la presencia de algún tipo de entierro ritual (Capac hucha). Por lo que sabemos, Reinhard recorrió todo el cráter volcánico sin encontrar más evidencias que las ya descritas (Beorchia 1985, 2001; Reinhard 1993 Ms). Queda abierta la posibilidad de realizar sondeos subacuáticos en ambas lagunas, que pudieron haber sido receptores de algún tipo de ofrenda.

\section{$*$ Conclusiones}

El volcán Chiliques tuvo y tiene una importancia ecológica, productiva, política y simbólica para los habitantes de la comunidad andina de Socaire. La evidencia etnoarqueológica recopilada desde finales de la década de 1950 con los trabajos de T. Barthel y luego retomado por Mariscotti de Görlitz, Tichy, Zuidema y Reinhard sugieren que este lugar constituyó un adoratorio indígena de alta montaña, al menos desde la llegada de los inkas a la zona.

14 Con una declinación magnética de $4^{\circ} 13^{\prime} \mathrm{W}$ (25/12/08). http: // recursos.gabrielortiz.com/index.asp. Esta orientación (al este) se vincula claramente con el culto solar, de amplia distribución en sitios arqueológicos ubicados en contextos inkas en el norte de Chile y noroeste de Argentina (Vitry 2001: 184, entre otros).
El Chiliques no solo da origen a las aguas que bajan desde la quebrada Nacimiento, $10 \mathrm{~km}$ al este de Socaire, sino coincide con la posición en el horizonte para la salida del sol en fechas cercanas al 24 de agosto, día de San Bartolomé, santo patrón de la comunidad de Socaire. Este fenómeno resultaría especialmente llamativo, si consideramos la posibilidad de un manejo y ajuste de un calendario solar de horizonte vinculado con las actividades agrícolas y el inicio del año de riego a principios del mismo mes de agosto. Sus implicancias sociales radican en la supuesta ritualización de los espacios conquistados por los inkas tras su llegada a tierras atacameñas.

Asimismo, en términos logísticos el acenso al volcán Chiliques no ofrece más dificultad técnica que su altitud ( 5778 m.s.n.m.) y lo abrupto de su pendiente. La existencia de un camino prehispánico desde la cota 4400 m.s.n.m. hasta la cumbre, un tambo incaico a los 4568 m.s.n.m., además de instalaciones logísticas a 5300 y 5560 m.s.n.m., por la ruta lógica que viene desde la laguna del Lejía, dan cuenta de las condiciones relativamente benignas de la zona, lo que sumado a la existencia de dos lagunas en su cumbre, habrían determinado la construcción de las estructuras $\mathrm{A}$, $\mathrm{B}$ y $\mathrm{C}$, además de pilas de madera, en un sector plano y amplio cercano a la cumbre principal.

Desde una perspectiva regional, podríamos plantear que este volcán constituyó un adoratorio incaico de primer orden (en la clasificación de Beorchia 1985), solo superado en espectacularidad por los volcanes Licancabur, en las cercanías del San Pedro de Atacama, y Llullaillaco frente al salar de Punta Negra. La existencia de arquitectura ceremonial segregada, ubicada en una de las precumbres (5770 m.s.n.m.), indica que este lugar podría haber sido un centro de peregrinaje, ya que presenta una distribución estratégica de las instalaciones logísticas (campamentos y caminos), así como arquitectura ceremonial de considerable perdurabilidad y visibilidad ubicada sobre superficies amplias y extensas, que permiten la participación masiva y periódica de peregrinos al adoratorio (siguiendo a Ceruti 1999: 55-73).

En Chiliques se generó un espacio físico para la realización de determinadas actividades, que incluyeron la participación de especialistas rituales y la movilización de recursos a los pies, laderas y cumbre del volcán. Como complemento, se realizan la petición de lluvias para la 
ceremonia de limpia de canales del mes de octubre en el centro ceremonial junto a la toma de agua en la quebrada Nacimiento. En este marco, el "morar o vivir en el mundo" estaría mediado por la ceremonia de petición de lluvias del mes de octubre y por la proyección simbólica del sistema de líneas hacia las montañas de la región. Para esta fecha, se exaltan las representaciones colectivas del espacio y el tiempo, intrínsecas al calendario agrícola y las divisiones entre el arriba y el abajo, la izquierda y la derecha, el día y la noche, lo visible y lo no visible.

Dentro de esta estructura, la incorporación del volcán Chiliques a los ritos anuales de fertilidad y al agua se realizó a través de la construcción de un sistema de líneas visuales (posiblemente ceques), proyectadas desde uno o varios centros (p.e., desde la iglesia antigua de Socaire), que buscó la regeneración del orden cósmico, la apropiación simbólica del entorno, la propiciación del recurso hídrico y finalmente la producción agrícola a través del sistema de andenerías, al menos desde la llegada de los inkas a la región.

Parece lógico, entonces, pensar en un sustrato preincaico de adoración a las montañas en la zona (Reinhard 1983, Schobinger 2001), debido a la existencia de cerámica de grupos locales atacameños del período Intermedio Tardío en el sector del tambo Chiliques. Siguiendo a Mariscotti de Görlitz (1978), podríamos especular también en la posibilidad de ritos de tipo "chamánico", asociados con las montañas y el uso de alucinógenos, de antigua data en Atacama, destinados a propiciar el agua y a los ancestros, sin el gasto de energía y la parafernalia introducida por los inkas ca. 1470 DC De esta manera, sugerimos la existencia de un sistema que incluyó, en palabras de otros autores (Iwaniszewski 2001; Tilley 1994), las categorías de lugar, sendero, horizonte y cenit como expresión del "vivir o morar en el mundo":

El "lugar" estaría representado por el centro ceremonial y la huaca en la precumbre del volcán Chiliques (estructura A).

Los "senderos" estarían simbolizados por las líneas de visión o convido a manera de sistema de ceques.

El "horizonte" sería encarnado por la proyección de una mano izquierda en el paisaje y la salida del sol para el 24 de agosto, como medida social del tiempo.

Y el "cenit" estaría presente en la forma de un gnomon o piedra vertical en el centro ceremonial, que simbolizó al Chiliques como parte del conjunto de cerros que propician la lluvia y el recurso hídrico dentro del sistema agrícola.

Agradecimientos A Victoria Castro y Varinia Varela por sus comentarios y aportes con respecto a la identificación cerámica. A Carolina Agüero, Gonzalo Pimentel y Gabriel Cantarutti, por sus dibujos de campo y referencias en torno al volcán Chiliques. A R. Tom Zuidema por sus acotaciones con respecto al calendario andino. A Johan Reinhard por permitir la utilización de sus planos. A Sebastián Ibacache por sus referencias en torno a la arqueología de alta montaña en Atacama. A P. Bustamante por la digitalización y construcción de las imágenes. A nuestras familias. Y especialmente a la comunidad atacameña de Socaire y sus Mayllkus tutelares por permitirnos trabajar en sus dominios.

\section{$*$ Referencias citadas}

AGÜERO, C., 2008 Ms. Notas de campo volcán Chiliques. Manuscrito en poder del autor.

ALDUNATE, C., 2001. El Inka en Tarapacá y en Atacama. En Tras la Huella del Inka en Chile, pp. 18-33. Museo Chileno de Arte Precolombino, Santiago.

BARTHEL, T., 1986 [1957]. El agua y el festival de primavera entre los atacameños. Allpanchis 28: 1-19.
BEORCHIA, A., 1985. El Enigma de los santuarios indígenas de alta Montana. Revista del Centro de Investigaciones Arqueológicas de Alta Montana (CIADAM), tomo 5. U.N.S.J. San Juan, Argentina.

BEORCHIA, A., 2001. Inventario de los objetos descubiertos en los adoratorios indígenas de altura. Revista del CIADAM 6: 281-314.

BITTMAN, B., L. NÚÑEZ y G. LE PAIGE, 1978. Cultura atacameña. Colección de Culturas Aborígenes. Departamento de Extensión Cultural del Ministerio de Educación, Santiago. 
El volcán Chiliques y el “Morar-en-el-Mundo” de unA COMUNidAd ATACAmeña del norte de Chile

BRADLEY, R., 2000. An Archaeology of Natural Places. Routledge, London.

CERUTI, M., 1999. Cumbres Sagradas del Noroeste Argentino. Eudeba, Editorial Universitaria de Buenos Aires, Argentina.

DESCOLA, P., 1998. Las cosmologías de los indios de la Amazonía. Zainak 17: 219-227.

DUVIOLS, P., 1976. La Capacocha. Mecanismo y función del sacrificio humano, su proyección geométrica, su papel en la política integracionista y en la economía redistributiva del Tawantinsuyu. Allpanchis 9: 11-57.

HIDALGO, B., 1992. Organización social, tradición y aculturación en Socaire, una aldea atacameña. Memoria de licenciatura, Facultad de Ciencias Sociales, Universidad de Chile, Santiago.

HIDALGO, J., 2001. El Tawantinsuyu, las Cuatro Partes del Mundo Inka. En Tras la Huella del Inka en Chile, pp. 5-17. Museo Chileno de Arte Precolombino, Santiago.

HUICI, V., 2007. Espacio, Tiempo y Sociedad. Akal, Madrid, España.

IBACACHE, S., 2007. Ascensos en el volcán Paniri: reconocimiento exploratorio de un adoratorio de montaña en la Región de Antofagasta. Memoria de Licenciatura, Facultad de Ciencias Sociales, Universidad de Chile, Santiago.

IWANISZEWSKI, S., 2001. Astronomía, materialidad y paisaje: reflexiones en torno a los conceptos de medio ambiente y de horizonte. Boletín de Antropología Americana 37: 217-240.

2007. La arqueología de alta montaña frente al paisaje montañés en México central: problemas, interpretaciones, perspectivas epistemológicas. En Páginas en la nieve, Estudios sobre la montaña en México, M. Loera, S. Iwaniszewski y R. Cabrera (Eds.), pp. 9-28. INAH, México.

2009. Por una astronomía cultural renovada. Complutum 20 : 23-37.

HORNBORG, A., 2006. Animism, fetishism, and objectivism as strategies for knowing (or not knowing the World). Ethnos $71(1)$ : 21-32.

KEARNEY, M., 1975. World view theory and study. Annual Review of Anthropology 4: 247-270.

LE PAIGE, G., 1978. Vestigios arqueológicos incaicos en las cumbres de la zona atacameña. Estudios Atacameños 6: 36-52
LLAGOSTERA, A., 1976. Hipótesis sobre la expansión incaica en la vertiente occidental de los Andes Meridionales. En Homenaje al R. P. Gustavo Le Paige s.j., H. Niemeyer (Ed.), pp. 203-218. Universidad del Norte, Antofagasta.

MARISCOTTI DE GÖRLITZ, A., 1978. Pachamama Santa Tierra, Indiana 8, Berlín, Gebr. Mann Verlag.

MOSELEY, M., 1992. The Incas and Their Ancestors. Thames and Hudson, London.

MOSTNY, G., 1954. Peine un Pueblo Atacameño. Publicación núm. 4 del Instituto de Geografía, Facultad de Filosofía, Universidad de Chile.

MOYANO, R., 2010. La mano de Dios en Socaire: estudio de un calendario agrícola en Atacama, norte de Chile. Tesis de magíster, Escuela Nacional de Antropología e Historia, México, D.F.

2011 Sub-tropical astronomy in southern Andes: the ceque system in Socaire, Atacama, northern Chile. En IAUS 278 Archaeoastronomy and Ethnoastronomy: Building Bridges between Cultures, C. Ruggles (Ed.), pp. 93-105. Cambridge University Press, Cambridge.

MURRA, J., 1972. El "control vertical" de un máximo de pisos ecológicos en la economía de las sociedades andinas. En Visita a la Provincia de León de Huanuco en 1562, Iñigo Ortiz de Zúñiga, J. Murra (Ed.), pp. 429-472. Universidad Emilio Valdizán Huanuco, Peru.

NÚÑEZ, L., 1999. Valoración minero-metalúrgica circumpuneña: menas y mineros para el Inka rey. Estudios Atacameños 18: 177-207.

PINO MANRIQUE, J., 1787. Descripción de la villa de Potosí y de los partidos sujetos a su intendencia.

REINHARD, J., 1983. Las montañas sagradas: un estudio etnoarqueológico de ruinas en las altas cumbres andinas. Cuadernos de Historia 3: 27-62.

1993 Ms. Chiliques: a report an Inca mountain ceremonial center in northern Chile. Manuscrito en poder del autor.

RODRÍGUEZ, G., 2003. El talátur: canto ceremonial de los atacameños. Hombre y desierto. Una perspectiva cultural 11: 57-72.

SANHUEZA, C., 2004. Medir, amojonar, repartir: territorialidades y prácticas demarcatorias en el camino incaico de Atacama (II Región, Chile). Chungara 36(2): 483-494. 
2005. Espacio y tiempo en los límites del mundo, los incas en el despoblado de Atacama. Boletín del Museo Chileno de Arte Precolombino 10(2): 51-77.

SHIAPPACASSE, V., V. CASTRO y H. NIEMEYER, 1989. Los desarrollos regionales en el Norte Grande (1000-1400 DC). En Culturas de Chile: Prehistoria desde sus orígenes hasta los albores de la Conquista, J. Hidalgo, V. Schiappacasse, H. Niemeyer, C. Aldunate e I. Solimano (Eds.), pp. 181-220. Editorial Andrés Bello, Santiago.

SCHOBINGER, J., 2001. El santuario incaico de cerro Aconcagua. Universidad Nacional de Cuyo, Mendoza.

SOUSTELLE, J., 2004. El Universo de los Aztecas. Fondo de Cultura Económica, México.

TICHY, F., 1983. El patrón de asentamientos con sistema radial en la meseta central de México: ¿sistemas ceque en Mesoamérica? Jahrbuch für Geschichte von Staat, Wirtschaft und Gesellschaft Lateinamerikas 20: 61-84.

TILLEY, C. 1994. A Phenomenology of Landscape: Places, Paths and Monuments. Berg, Oxford.

2008. Phenomenological Approaches to Landscape Archaeology. En Handbook of Landscape Archaeology, B. David y J. Thomas (Eds.), pp. 271-276. World Archaeological Congress, Left Coast Press, California.

TRONCOSO, A., 2001. Espacio y poder. Boletín de la Sociedad Chilena de Arqueología 32: 10-23.

URIBE, M., 2000. La arqueología Inka en Chile. Revista Chilena de Antropología 15: 63-97.
2004. El Inka y el poder como problemas de la arqueología del Norte Grande. Chungara 36 (2): 313-324.

URIBE, M., y L. ADÁN, 2004. Acerca del dominio Inka, sin miedo, sin vergüenza. Chungara 36(3):467-480.

URIBE, M., y C. CARRASCO, 1999. Tiestos y piedras talladas de Caspana: La producción alfarera y lítica en el período Tardío del Loa Superior. Estudios Atacameños 18: 55-71.

VALENZUELA, A., 2000. Socaire: Contexto, problemas y transformaciones en la agricultura de un pueblo atacameño. Informe Final de Práctica Profesional en Antropología Social, Universidad de Chile, Santiago.

VITRY, C., 2001. ¿Por qué ruinas a tanta altura?: hipótesis explicativas. Revista del CIADAM 6: 184-185.

ZIÓLKOWSKI, M., 1987. Las Fiestas del Calendario Metropolitano Inca: Primera Parte. Ethologia Polona 13: 183-217.

ZUIDEMA, R. T., 1989. Reyes y guerreros: Ensayos de la cultura andina. Ediciones Fomciencias, Lima.

1990. Ceques and Chapas: an Andean Pattern of Land Partition in the Modern Valley of Cuzco. En Circumpacifica Festschrift für Thomas S. Barthel, Bruno Illius y Matthias Laubscher (Eds.), pp. 627-643. Peter Lang, Frankfurt.

1995 [1964]. El sistema de ceques del Cuzco. Pontificia Universidad Católica del Perú, Lima.

2011. El Calendario Inca: Tiempo y espacio en la organización ritual del Cusco; La idea del pasado. Fondo Editorial del Congreso del Perú y Pontificia Universidad Católica del Perú, Lima. 